\title{
Continuing Validation of Computational Fluid Dynamics For Supersonic Retropropulsion
}

\author{
Daniel Guy Schauerhamer* \\ Jacobs Technology, Houston, TX \\ Kerry A. Trumble ${ }^{\dagger}$ \\ NASA Ames Research Center, Moffett Field, CA \\ Bil Kleb, ${ }^{\ddagger}$ Jan-Reneé Carlson ${ }^{\S}$ and Karl T. Edquist $₫$ \\ NASA Langley Research Center, Hampton, VA
}

\begin{abstract}
A large step in the validation of Computational Fluid Dynamics (CFD) for Supersonic Retropropulsion (SRP) is shown through the comparison of three Navier-Stokes solvers (DPLR, FUN3D, and OVERFLOW) and wind tunnel test results. The test was designed specifically for CFD validation and was conducted in the Langley supersonic 4'x4' Unitary Plan Wind Tunnel and includes variations in the number of nozzles, Mach and Reynolds numbers, thrust coefficient, and angles of orientation. Code-to-code and code-to-test comparisons are encouraging and possible error sources are discussed.
\end{abstract}

\section{Nomenclature}

\begin{tabular}{llll}
$\alpha$ & Angle of Attack & $C_{T}$ & Thrust Coefficient, $T / q A_{\text {ref }}$ \\
$\phi$ & Roll Angle & $L$ & Model Length, $10.2 \mathrm{in}$ \\
$A_{\text {ref }} \quad$ Reference Area, $19.63 \mathrm{in}^{2}$ & $L_{r e f}$ & Reference Length, $5.0 \mathrm{in}$ \\
$C_{A, \text { aero }}$ Aerodynamic Contribution to Axial Force & $q$ & Dynamic Pressure, $p \mathrm{si}$ \\
\multicolumn{2}{l}{ Coefficient } & $R$ & Model Radius, $2.5 \mathrm{in}$ \\
$C_{A, t o t a l}$ Total Axial Force Coefficient, $C_{T}+C_{A, \text { aero }}$ & $r$ & Radial Coordinate \\
$C_{m} \quad$ Pitching Moment Coefficient & $T$ & Thrust, $l b f$ \\
$C_{N} \quad$ Normal Force Coefficient & $X$ & Axial Coordinate \\
$C_{P} \quad$ Pressure Coefficient & &
\end{tabular}

\section{Introduction}

GUPERSOnic Retropropulsion (SRP) is a viable means for deceleration of high mass vehicles entering into Nthe Martian atmosphere. ${ }^{1,2,3,4,5,6}$ Previous methods of deceleration are not scalable for exploration type vehicles which can potentially weigh tens of metric tons. Since ground and flight testing of SRP at entry conditions can be difficult and cost-prohibitive, the development of this enabling technology can be enhanced with the ability to predict the flowfield numerically using Computational Fluid Dynamics (CFD).

SRP results in a complex flow structure involving shocks, shear layers, recirculation and stagnation regions, which makes validation of the CFD methods a high priority. The validation process includes using multiple CFD codes to compare to historical ${ }^{7}$ and recent wind tunnel tests. ${ }^{8}$ Through code-to-code and code-to-test comparisons, best practices in gridding, numerical method selection, and solution advancement are established, and validity is added to the CFD methods. With continuing validation, confidence can be built for using CFD to predict Mars entry conditions. ${ }^{9}$

\footnotetext{
*Aerospace Engineer, Applied Aeroscience and CFD Branch, EG-3, Member

${ }^{\dagger}$ Research Scientist, Aerothermodynamics Branch, MS 230-2, Senior Member

${ }^{\ddagger}$ Aerospace Engineer, Aerothermodynamics Branch, MS 408A, Lifetime Member

$\S$ Aerospace Engineer, Computational Aero-Sciences Branch, MS 128, Senior Member

『Aerospace Engineer, Atmospheric flight and Entry Systems Branch, MS 489, Senior Member
} 
Three CFD codes are being applied to SRP: DPLR (Data Parallel Line Relaxation) ${ }^{10}$ FUN3D (Fully Unstructured Navier-Stokes Three-Dimensional), ${ }^{11,12}$ and OVERFLOW (OVERset grid FLOW solver). ${ }^{13}$ The codes all solve the Reynolds Averaged Navier-Stokes equations, but differ in implementation, grid type, and numerical methods. The focus of this paper will be on the comparison of the CFD codes to a recent wind tunnel test which was designed primarily for CFD validation. The experiment was conducted by the NASA Exploration Technology Development Program in the Langley supersonic 4'x4' Unitary Plan Wind Tunnel in July, 2010. ${ }^{14,15,16}$ The cases that will be presented all have a free stream Mach number of 4.6 and a Reynolds number of $1.5 \mathrm{E}+06$ per foot, but vary by the number of nozzles $(0,1,3$, or 4 nozzles), thrust coefficient $\left(C_{T}=T / q A_{r e f}=2,3\right)$, angle of attack $(0,12,16$, and 20 degrees $)$, and roll angle ( 0 and 180 degrees). Time-accurate CFD simulations were conducted due to the inherent unsteadiness of the flowfields.

Qualitative comparisons of the flow structure will be made by comparing CFD to high-speed Schlieren images, and quantitative comparisons will be made by comparing averaged surface pressure with pressure tap data from the tunnel. Unsteady shedding frequencies of the CFD solutions are also compared to highfrequency pressure gauges from the test.

This paper will first introduce SRP, the CFD codes, and the wind tunnel test. Then it will present code-to-code and code-to-test comparisons, discuss the results including modeling strengths and weaknesses, and offer conclusions of the study.

\section{SRP Flow Structure}

Figure 1 shows a representative wind tunnel model that employs SRP along with the resulting flowfield. The vehicle is a sphere cone with a single nozzle in the center and a sting for mounting it in the tunnel. In supersonic flow a bow shock forms. As an opposing jet is initiated, the bow shock is pushed upstream as the apparent body frontal area is increased with the appearance of a barrel plume. The barrel plume contains free shear layers as well as a terminal shock. Between the terminal and bow shocks is an interface or contact surface where opposing velocities meet and go to zero. With the barrel plume, recirculation regions appear as well as a triple-point, where it can be said that three types of flow meet- supersonic jet flow, subsonic shock-layer flow, and subsonic recirculating flow.

This is an example of a single jet flow at a relatively high thrust coefficient. Other modes exist depending on jet-to-free stream pressure ratios, including a long-jet penetration mode at low ratios. With multiple nozzles, interaction between barrel plumes may also exist, and the apparent body frontal area can change depending on the location of the nozzle on the model face, and orientation angle of the nozzles. ${ }^{17,18}$

\section{Description of CFD Solvers}

The three solvers applied to the SRP problem differ in implementation, grid type, and numerical methods. DPLR and FUN3D are finite-volume while OVERFLOW is finite-difference. DPLR uses cell-centered structured overset grids, while OVERFLOW uses node-centered structured overset grids. FUN3D employs node centered unstructured grids. With these differences between codes, much is to be learned through code-to-code comparison when applying them to a single set of problems.

This paper builds from reference [9], which focuses on a single run of the Langley Unitary Wind Tunnel test. In reference [9], an in-depth look at grid and time resolution, observed order of accuracy, and the establishment of best practices is described in

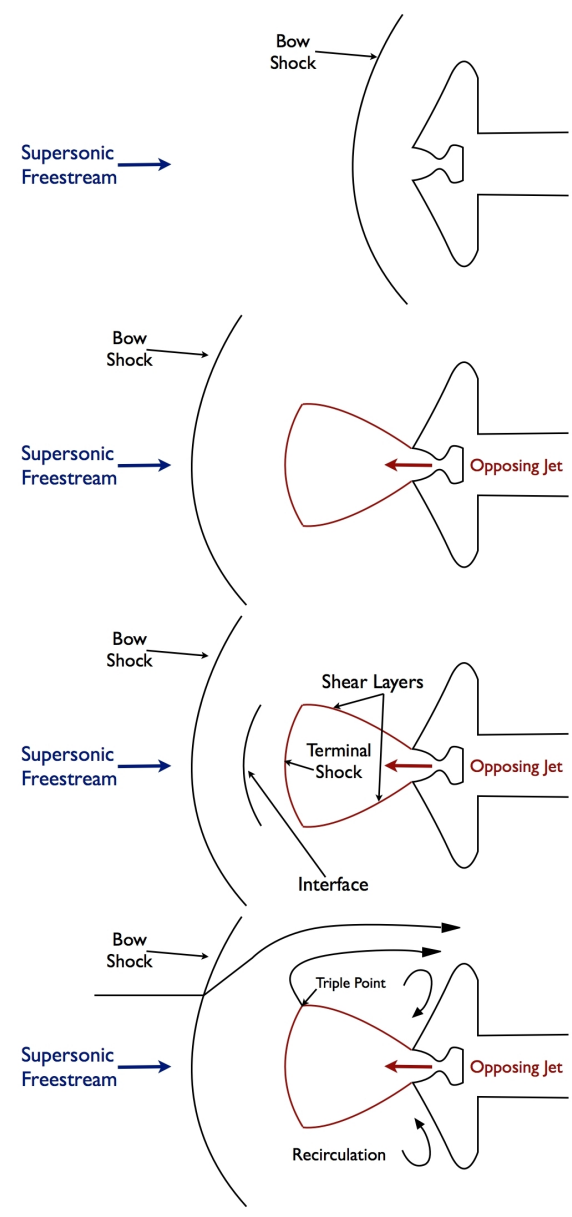

Figure 1. SRP flow structure description diagrams. 
detail. The following will be brief descriptions of each code including the numerical methods used by each in this study.

\section{III.A. DPLR}

The DPLR CFD code is a parallel, structured multi-block, finite-volume code with overset grid capability that solves the Reynolds-Averaged Navier-Stokes (RANS) equations for continuum flow, including finite-rate chemistry and thermal non-equilibrium. In the present study, the thermally- and calorically-perfect RANS equations for air are solved implicitly with 1st-order time accuracy. Inviscid fluxes are formed via a modified Steger-Warming flux vector splitting ${ }^{19}$ with 3rd-order Monotone Upwind Scheme for Conservation Laws (MUSCL) extrapolation ${ }^{20}$ subject to a minmod limiter $^{21}$ and 2 nd-order trapezoidal rule flux integration. The viscous terms are computed with 2nd-order spatial accuracy with a central difference approach. For the present analysis, the Menter's Shear-Stress Transport (SST) turbulence model ${ }^{22}$ was employed with a vorticity-based production term and no compressibility corrections.

\section{III.B. FUN3D}

FUN3D contains a node-based finite-volume unstructured flow solver. For this study, FUN3D was run with a selectively-dissipative version of the Low-Dissipation Flux Splitting Scheme (LDFSS) inviscid flux function $^{23}$ and a modified Van Albada ${ }^{24}$ limiter according to White. ${ }^{25}$ Direct Eddy Simulation (DES) turbulence modeling was used with Spalart-Allmaras (SA) ${ }^{26}$ as the submodel. Cases were also completed with the compressible RANS equations loosely coupled to Menter's SST turbulence model with a vorticity-based production term. Node-based conservative variables are computed by driving a 2nd-order accurate spatial residual to stead-state with a point-implicit iterative method. A modified, optimum 2nd-order backward difference formula (BDF) scheme is used in conjunction with a temporal error controller that assured design order. $^{27}$

\section{III.C. OVERFLOW}

OVERFLOW 2 is an implicit Reynolds Averaged Navier-Stokes (RANS) flow solver that utilizes structured overset grids. For the current work, the HLLE++ numerical flux function ${ }^{28}$ with the Van Albada limiter was used for spatial terms, and the Symmetric Successive Over Relaxation (SSOR) algorithm with dual time stepping using Newton sub-iterations for temporal terms. All viscous terms were included, and the SST turbulence model with strain-based production was employed with Wilcox's realizability constraint. The overall scheme is 2nd-order accurate in space and time. The calculation of the inviscid fluxes for both the flow solver and the turbulence model use 3rd-order accurate MUSCL reconstruction and 2nd-order flux quadrature. For the single and triple nozzle configurations, DES turbulence modeling with SST as the submodel was used, and for the baseline and quad nozzle configurations, RANS SST turbulence modeling was used.

\section{SRP Wind Tunnel Test}

Test 1853 in the Langley supersonic Unitary Plan Wind Tunnel (LaUPWT) was designed specifically for SRP CFD validation. The model was a $70^{\circ}$ sphere-cone forebody with a cylindrical side body with a 5 inch diameter. The model included four nozzles which could be plugged to offer a $0,1,3$, or 4 nozzle configuration. One nozzle was located at the center of the forebody, and three were oriented at a constant $1 / 2$ radial coordinate every $120^{\circ}$. Air was used as both the freestream and jet gases. The test data included high speed Schlieren movies and pressure readings from 172 originally planned taps including nine $40 \mathrm{kHz}$ pressure transducers. From these data, it is possible for qualitative comparisons with CFD of flow structure and unsteady behavior with the Schlieren movies, as well as averaged surface pressure comparisons with the pressure taps. The high frequency pressure transducers also allows frequency comparisons to measure the accuracy of the CFD unsteadiness.

The test run matrix included four nozzle configurations: 0, 1 (center), 3 (peripheral), and 4 (center and peripheral). Three Mach numbers were tested: 2.4, 3.5, and 4.6. The Re/ft for the two lower Mach numbers was $1 \mathrm{M}$, and for Mach $4.6, \mathrm{Re} / \mathrm{ft}$ was $1.5 \mathrm{M}$. Thrust coefficients ranged from 0.5 to 3 , with isolated runs up to 6 . Angles of attack swept from $-8^{\circ}$ to $20^{\circ}$. A full description of the test can be found in reference [14]. 
Figure 2 is a snapshot of the model in the triple nozzle configuration in the test section. Figure 3 shows diagrams of the model face and side-body pressure tap layouts.

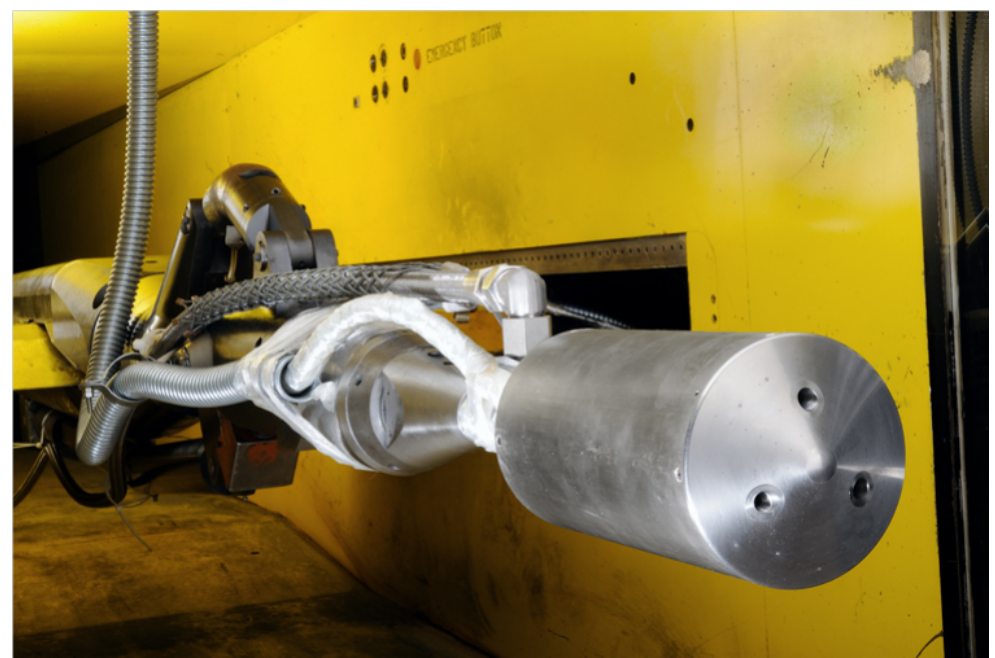

Figure 2. SRP test model in the 3 nozzle configuration in the NASA Langley UPWT $4 \times 4$ supersonic tunnel (test section 2).

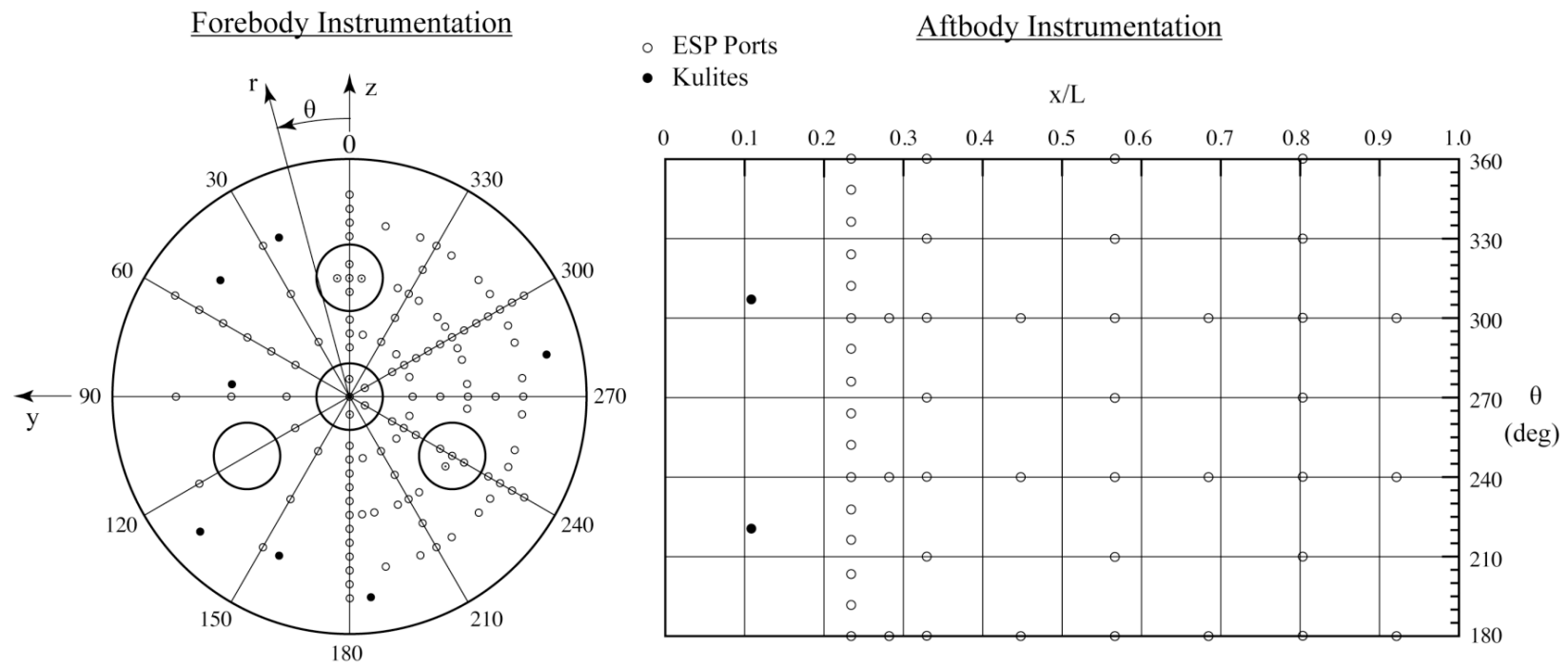

Figure 3. Pressure tap layout on test model. Left image is the front face of the model and the right image is the side body. Filled circles represent the high frequency pressure transducers.

\section{IV.A. Wind Tunnel Uncertainty}

Wind tunnel uncertainty was calculated using an entirely statistical approach based on comparing multiple measurements of surface pressure coefficient in a specially designed sampling technique. ${ }^{29}$ The uncertainty contains contributions from random sources (instrumentation drift, hysteresis, etc), flowfield non-uniformity, and model geometry/instrumentation uncertainties. The final pressure coefficient uncertainty for Mach 4.6 is seen in Table 1, where it is seen that flowfield non-uniformity is the largest contributor. For the CFD comparisons, $3 \sigma$ uncertainty bars were applied to the test data.

The uncertainty analysis was conducted on the baseline (no jet) configuration. As such, it does not include contributions introduced by the jets or the unsteadiness in the plumes. Although these contributions cannot be quantified directly, scatter in the results of repeat blowing cases were largely contained within certainty limits. $^{29}$ 
Table 1. Wind Tunnel Uncertainty

\begin{tabular}{cccc}
\hline Mach & Source & $\sigma$ & \% Total \\
\hline 4.6 & Random & 0.00294 & 15 \\
4.6 & Flow Field & 0.00637 & 71 \\
4.6 & Geometry & 0.00276 & 13 \\
4.6 & Total & 0.00754 & 100 \\
\hline
\end{tabular}

\section{Results}

A total of 18 cases were simulated with the CFD solvers. They focused on the higher Mach number (4.6) to decrease the probability of wall interference in the tunnel which had large boundary layers in the test section. The cases vary in angle of attack, roll angle, thrust coefficient, and the number of nozzles (see Table 2).

Images of the grids used for each code are seen in Figure 4. Each grid has a different topology but all focus refinement in the shock interaction region.

Comparisons of results between the three CFD flow solvers and the wind tunnel data are shown in Figures 5 through 26. A general explanation of the plots will be offered here and a full discussion of the results will be presented later.

The black and white images labeled as "TEST" are instantaneous images gathered from the high speed Schlieren system from the LaUPWT test. Colored flow visualizations from CFD codes show either Mach or $C_{P}$ contours. Black and white flow visualizations from the CFD codes are simulated Schlieren or shadowgraph representations generated through volume integration as described by Yates. ${ }^{30}$ The exception would be the OVERFLOW run 165 cases which are symmetry plane slices of the log of the density gradient magnitude colored in grayscale. To account for $\phi=180^{\circ}$ rotations, negative angles of attack were used for the FUN3D results.

Columns in the flow visualizations montages are snapshots in time (labeled Time 1, Time 2, Time 3, and Time 4), but they do not correlate between the CFD simulations or test Schlieren. Each point in time was chosen to best represent the behavior observed in the flowfield.

In the line plots, comparisons between the codes and experimental values of the averaged surface $C_{P}$ are shown using two coordinate systems. The first shows pressures on the model face in radial coordinates normalized by the model radius. Data from both $\phi=0^{\circ}$ and $\phi=180^{\circ}$ (see Figure 3) are shown on the same plot. The second set of plots show pressures down the length of the body. Here the $X$ coordinates are normalized by the model length.

Forces and moments as a function of time are also plotted as a code-to-code comparison. The test did not include a balance and integration of the pressure tap values only yield averaged aerodynamic loads. Total axial force is plotted, which is a summation of the aerodynamic and thrust components to axial force. Through these plots it is possible to compare the level of unsteadiness between the codes as well as gain an understanding of how much the unsteadiness may influence the stability of a vehicle at these conditions. The force and moment integration was conducted on the model face and side; it did not include the model base. The reference length and area used in nondimensionalizing the coefficients are seen in Table 3; the reference length is the diameter of the model, and the reference area is the projected frontal area. The moment reference center was the nose of the model. The time period shown in the force and moment coefficient plots do not represent the total run time of the CFD codes but was based on the code which was run for the smallest amount of time. 
Table 2. CFD Run Matrix

\begin{tabular}{ccccc}
\hline Run Number & Nozzles & $C_{T}$ & Angles of Attack $(\alpha)$ & Roll Angle $(\phi)$ \\
\hline 283 & 0 & N $/ \mathrm{A}$ & $0^{\circ}, 12^{\circ}, 20^{\circ}$ & $0^{\circ}$ \\
165 & 1 & 2 & $0^{\circ}, 12^{\circ}, 20^{\circ}$ & $180^{\circ}$ \\
262 & 3 & 3 & $0^{\circ}, 12^{\circ}, 16^{\circ}$ & $0^{\circ}$ \\
263 & 3 & 3 & $0^{\circ}, 12^{\circ}, 16^{\circ}$ & $180^{\circ}$ \\
307 & 4 & 2 & $0^{\circ}, 12^{\circ}, 20^{\circ}$ & $0^{\circ}$ \\
311 & 4 & 2 & $0^{\circ}, 12^{\circ}, 20^{\circ}$ & $180^{\circ}$ \\
\hline
\end{tabular}

Table 3. Reference Quantities for Force and Moment Coefficients

\begin{tabular}{cc} 
Reference Length $\left(L_{r e f}\right)$ & Reference Area $\left(A_{r e f}\right)$ \\
\hline $5.0 \mathrm{in}$ & $19.63 \mathrm{in}^{2}$
\end{tabular}

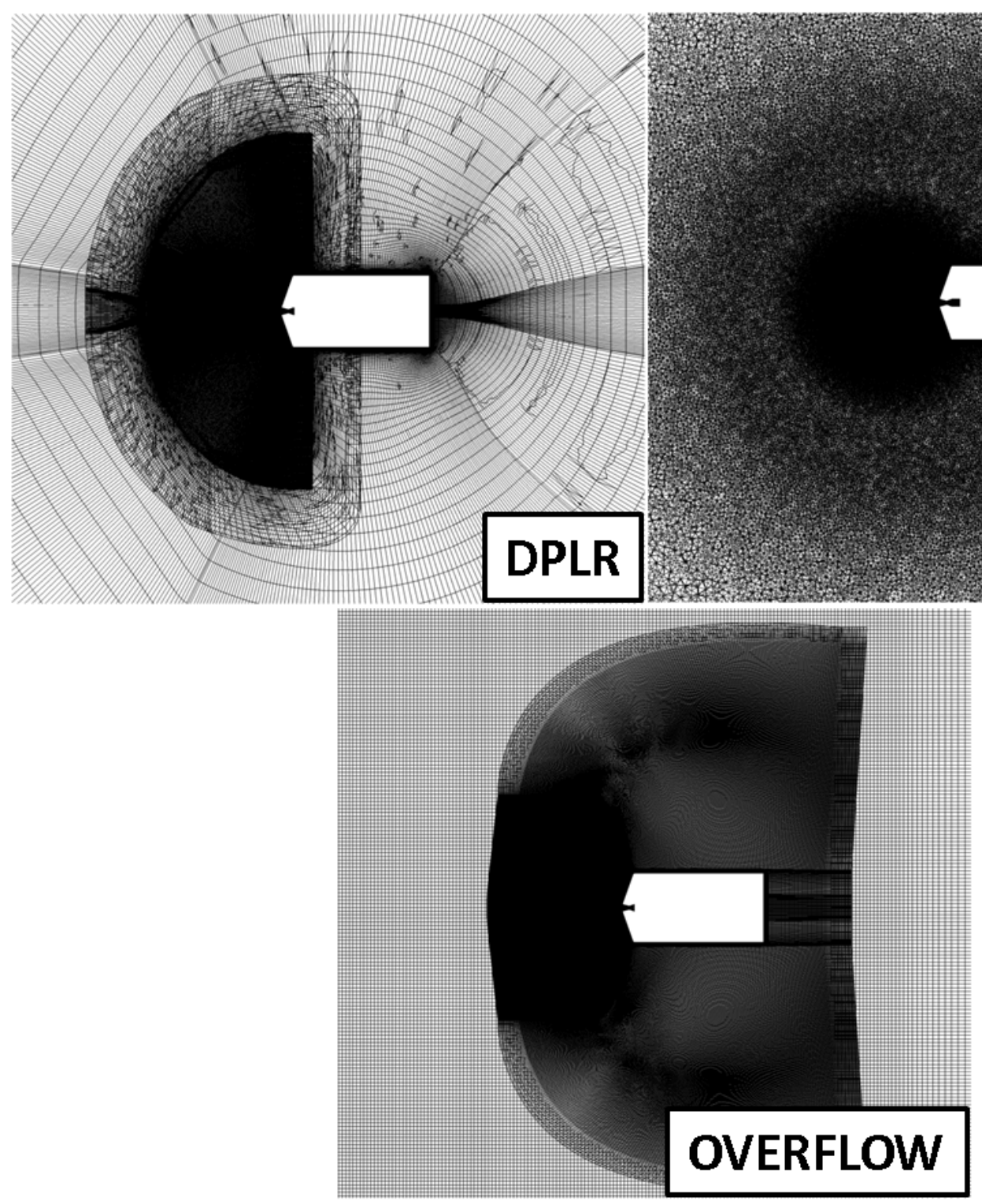

Figure 4. Symmetry plane slices of the grids used for each code. 


\section{V.A. Run 283- 0 Nozzles}

Run 283 is a baseline zero nozzle case resulting in a steady supersonic blunt-body flow, which is simpler than the powered cases. As expected, each code compared well to each other and to the test in shock standoff distances and surface $C_{P}$. The DPLR visualizations show very little flowfield upstream of the bow shock which demonstrates the grid adaptation feature in the DPLR code.

Overall, the CFD codes predict higher pressure on the model face than the experiment, most of which is contained inside the error bars. However, the pressure at the nose is an area of deviation between the CFD codes and the test data for $\alpha=12^{\circ}$ and $\alpha=20^{\circ}$. The Rayleigh pitot formula gives the maximum $C_{P}$ for Mach 4.6 flow to be 1.803. This correlates to the $C_{P}$ at the nose for $\alpha=0^{\circ}$. The test data and OVERFLOW results show a slightly lower value than 1.803 while the DPLR and FUN3D results are closer to the theoretical value. This may show that the test data is biased slightly low, perhaps due to flow non-uniformity in the tunnel, but this deviation at the nose for $\alpha=0^{\circ}$ is still within the uncertainty bars.

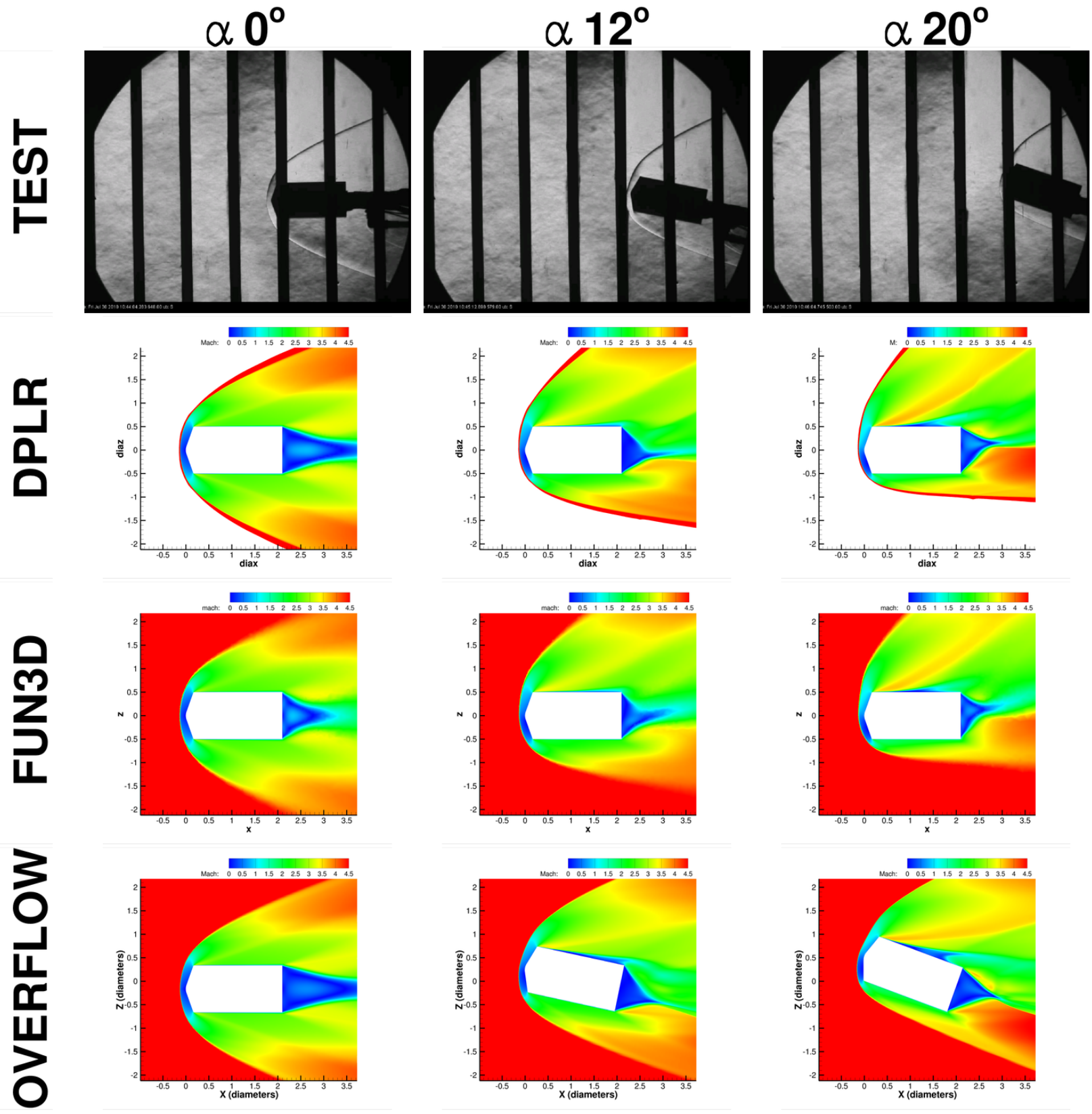

Figure 5. Flow visualizations of run 283, baseline zero nozzles. 

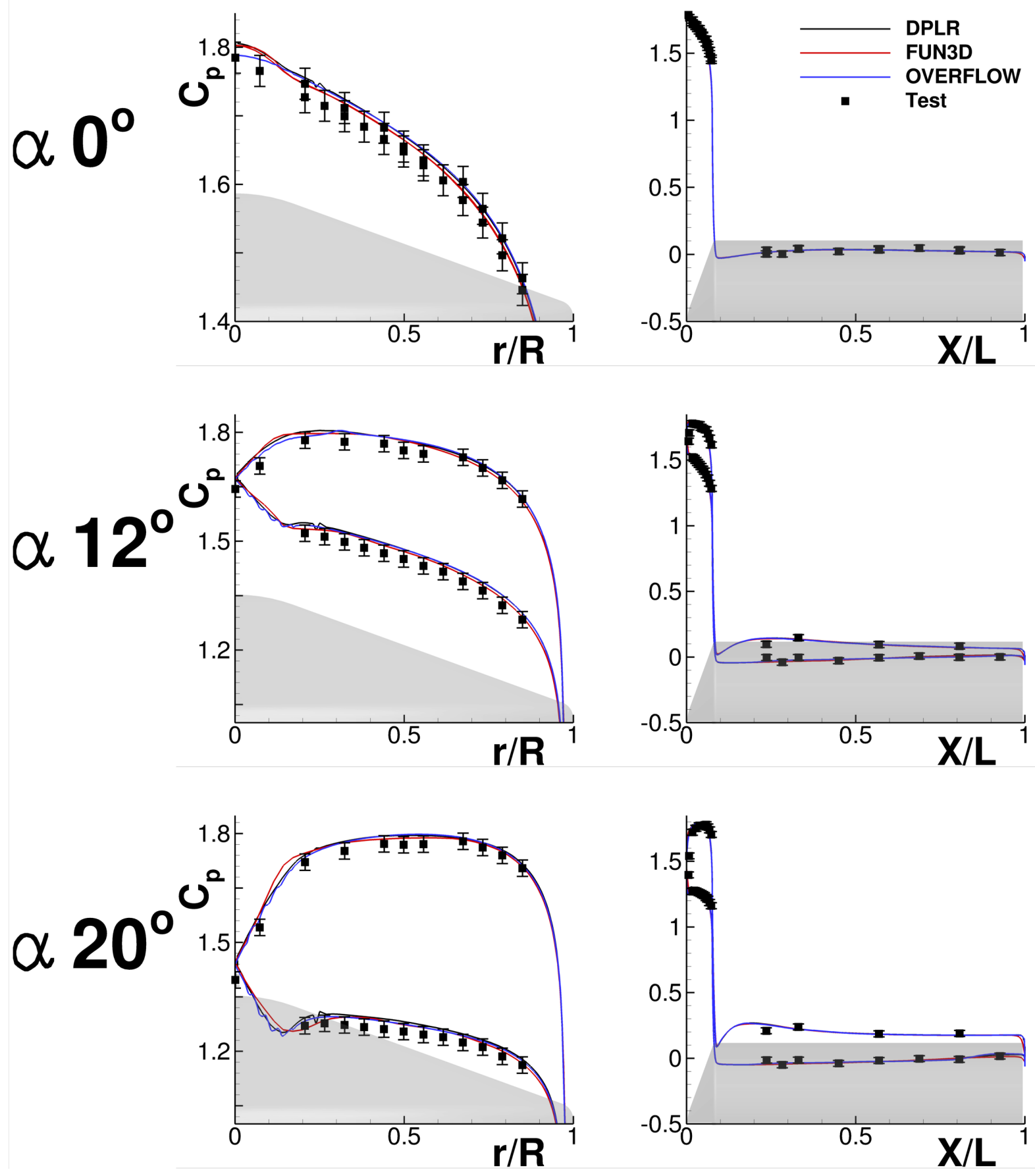

Figure 6. Pressure coefficient on model surface for run 283, baseline zero nozzles. 


\section{V.B. Run 165, Single Nozzle, $C_{T} 2$}

Run $165 \alpha=0^{\circ}$ was used to establish the best practices for each code. ${ }^{9}$ It was chosen because of its periodic unsteadiness, which simplified comparisons. The unsteadiness can be described as an oscillation of the triple point (described three dimensionally as an annular ring) which created pressure waves that propagate up to the bow shock causing a minimal effect, and also propagate to the model. The waves reflect off the model face and in turn off the barrel plume shear layers which causes another oscillation of the triple point.

Each code captured this unsteadiness to a different degree, the differences in turbulence modeling and grid refinement being the key contributors to the deviations. The level of unsteadiness can be seen in the force and moment plots in Figure 10, OVERFLOW and FUN3D having larger oscillation amplitudes than DPLR, with the DPLR case trending toward a steady solution.

An effect of capturing the described unsteady effects can be noted in the model face surface $C_{P}$. The codes that captured the unsteadiness captured the pressure wave as it reflected off the model face, and in turn a higher averaged pressure near the nozzle was predicted. This trend is also seen in the wind tunnel data. However, the tunnel uncertainties are large enough to envelope the CFD data that did not capture the unsteady effects.

For $\alpha=12^{\circ}$, the flow unsteadiness becomes less periodic. A shedding from the windward side of the triple point occurred which was again captured to different degrees between the codes. More deviation between the codes and test is seen in the $C_{P}$ plots. All codes predict pressures on the side body within test uncertainties, but only OVERFLOW does for the complete model face. More deviation on the windward side of the face is seen, especially as $r / R$ approaches 1 , or approaching the shoulder. FUN3D overpredicts pressure near the shoulder while DPLR underpredicts.

For $\alpha=20^{\circ}$, the flow unsteadiness loses all periodicity. Large shedding occurs randomly, and a large run time was required to obtain meaningful averages from the CFD cases (the same can be said for all randomly unsteady cases in this paper). The CFD results mostly fall inside the tunnel uncertainty for averaged surface $C_{P}$ even though different behaviors are seen in the simulations. The DPLR results appear to have a periodic unsteadiness in the force and moment plots while the OVERFLOW and FUN3D results show a more chaotic behavior.
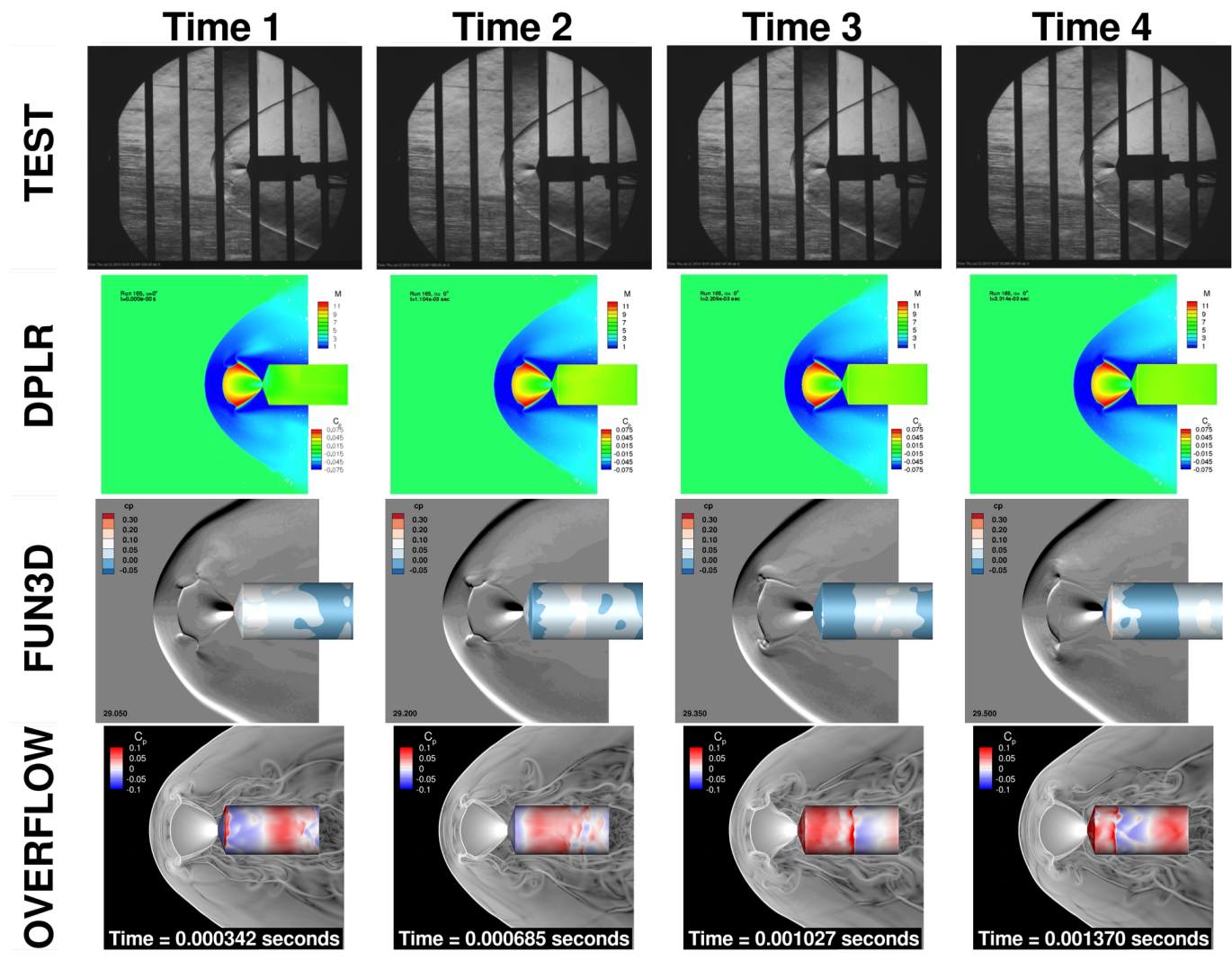

Figure 7. Flow visualizations of run $165, \alpha 0^{\circ}$, single nozzle, $C_{T} 2$. 


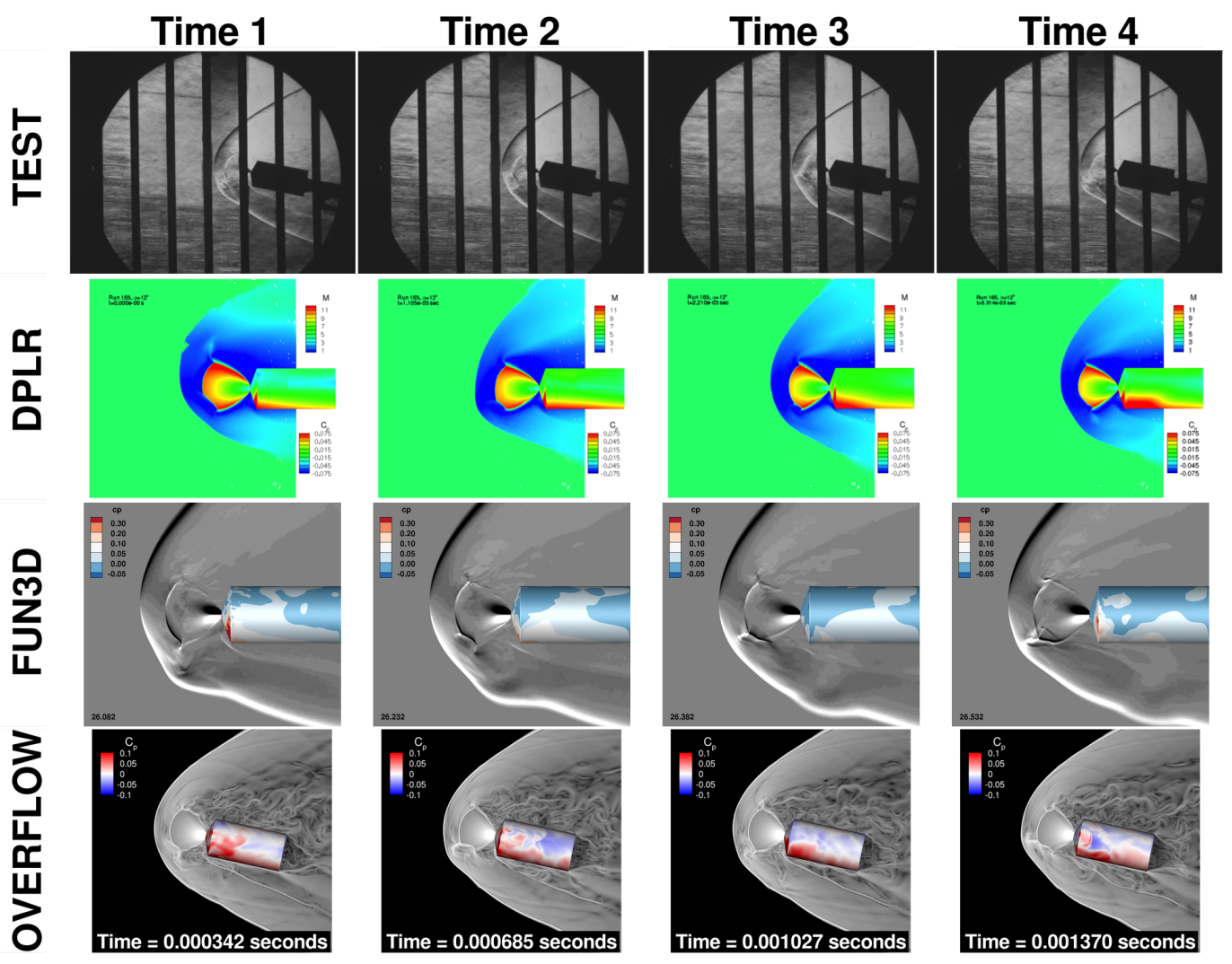

Figure 8. Flow visualizations of run $165, \alpha 12^{\circ}$, single nozzle, $C_{T} 2$.
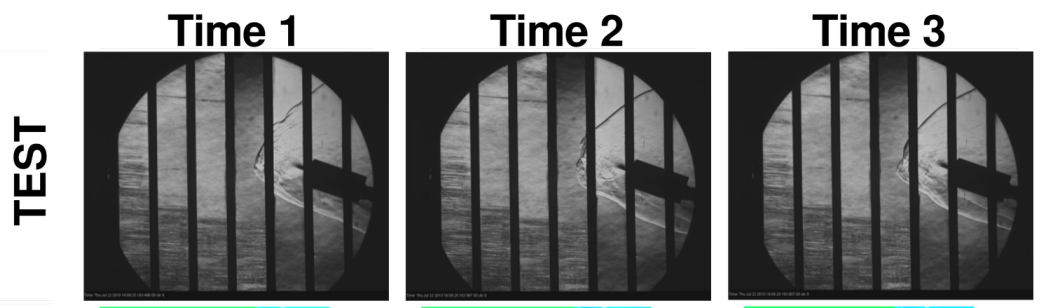

Time 4
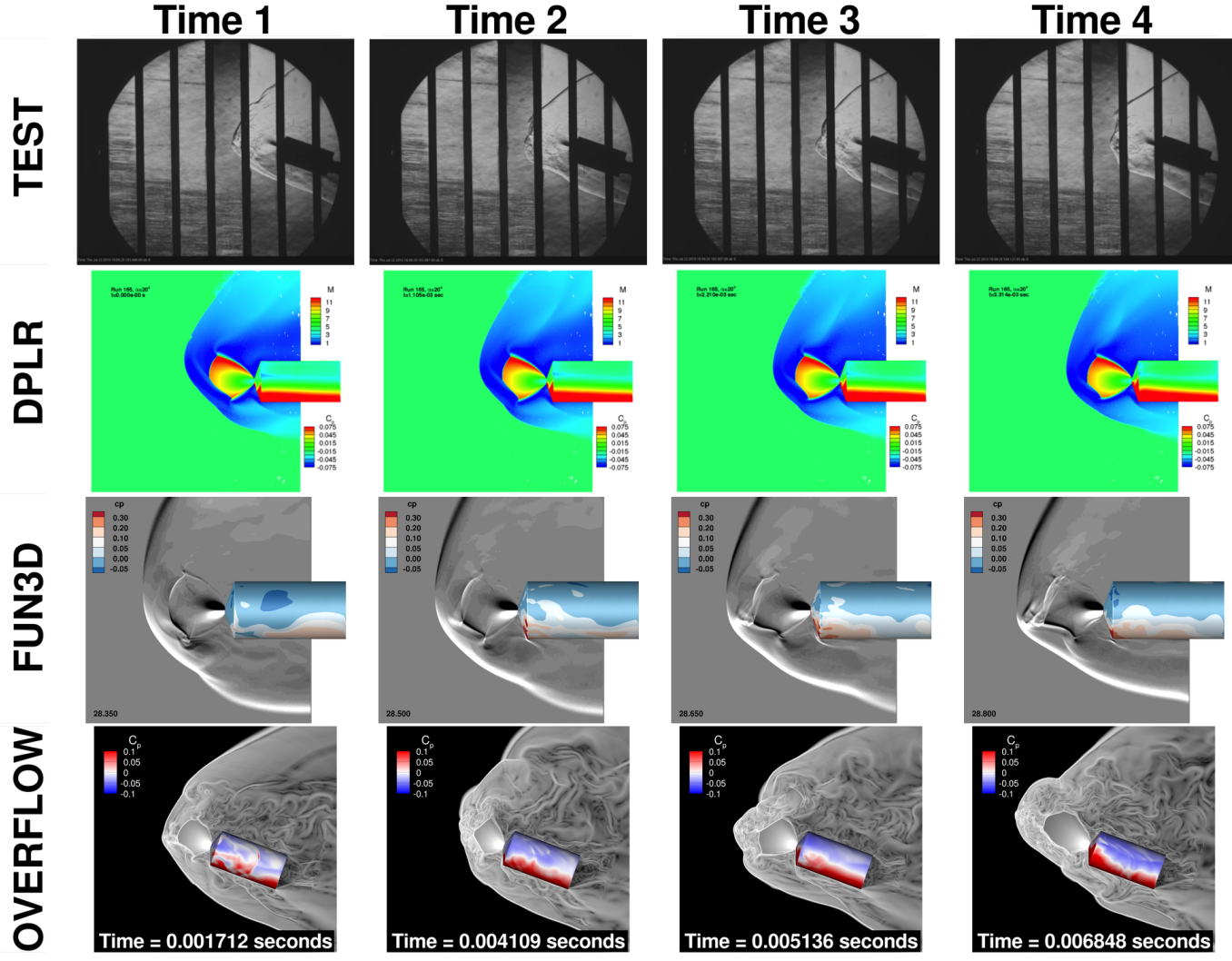

Figure 9. Flow visualizations of run $165, \alpha 20^{\circ}$, single nozzle, $C_{T} 2$. 

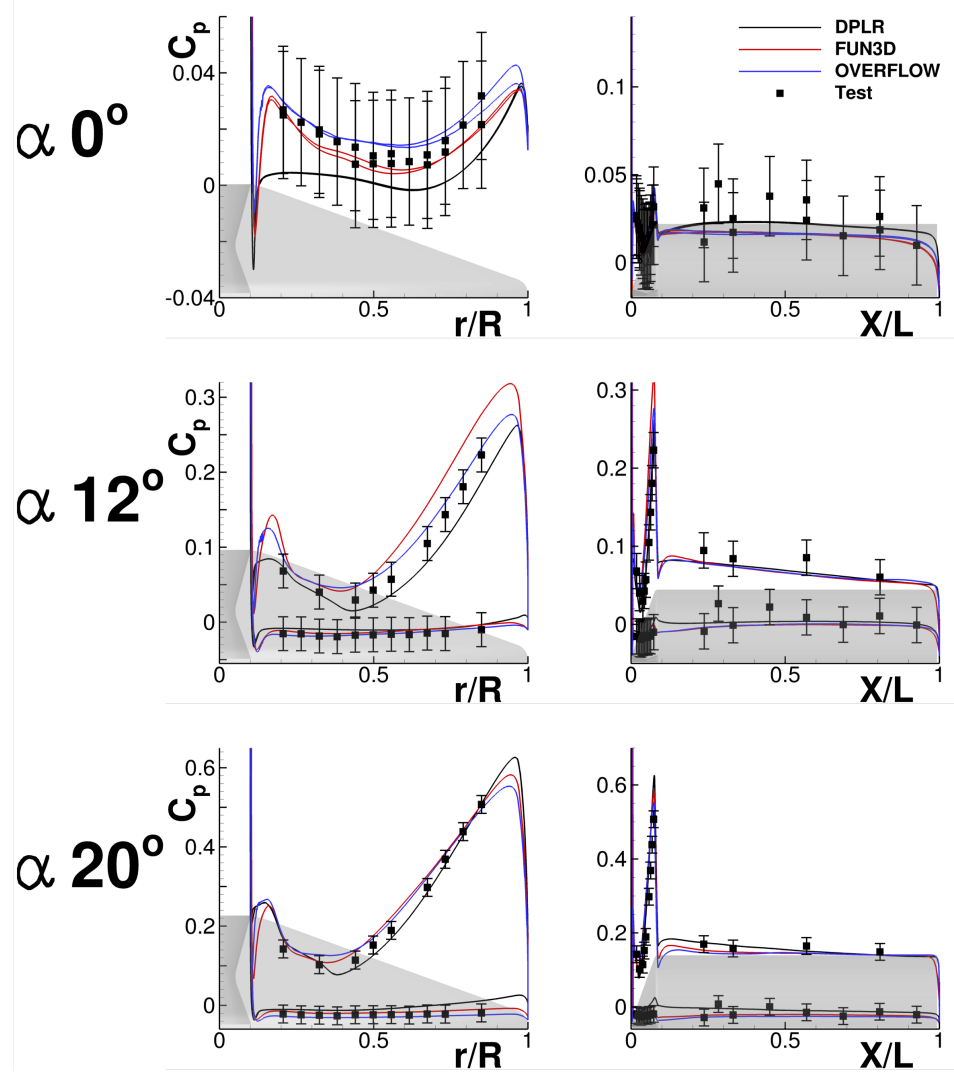

(a) Model surface $C_{P}$
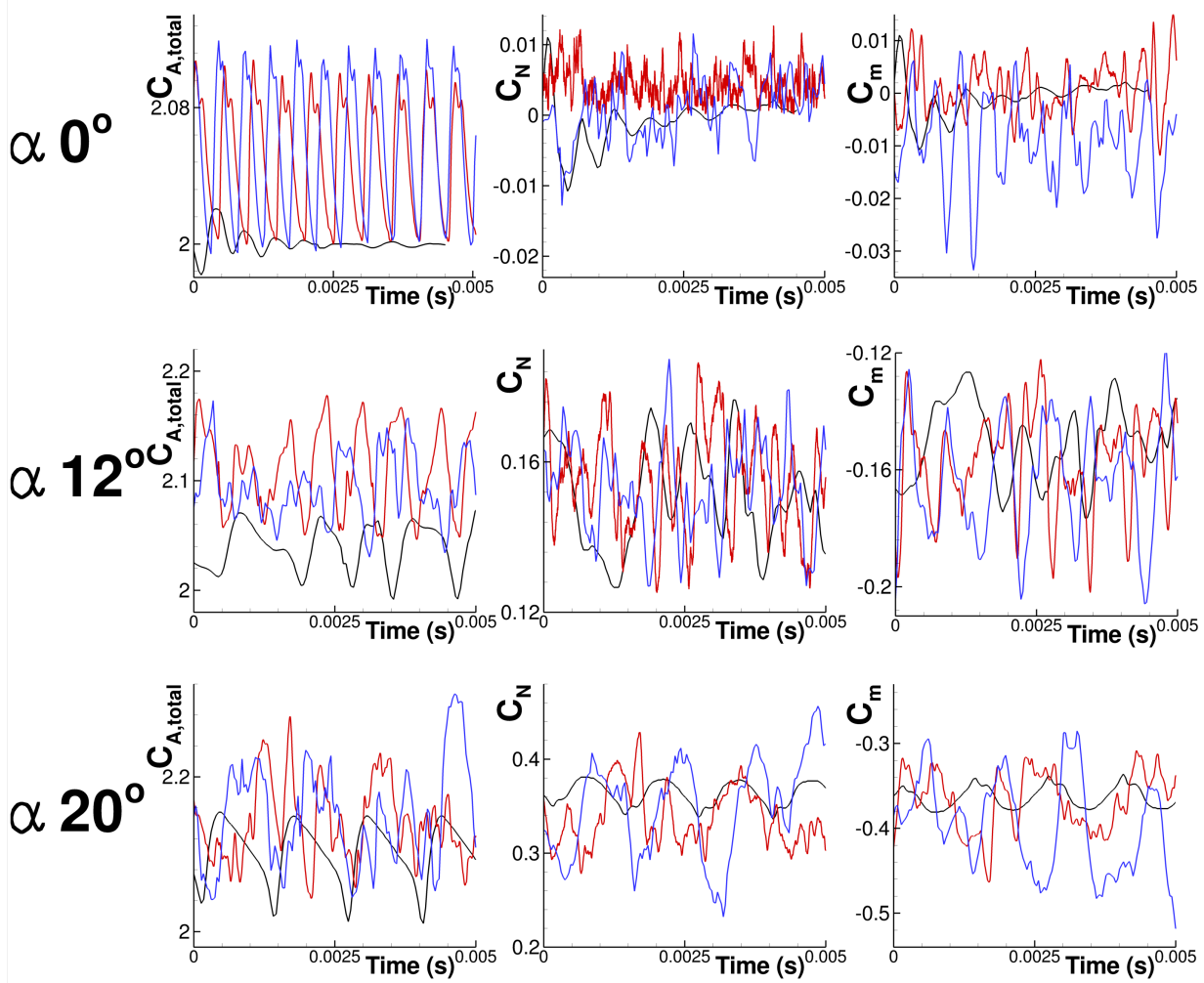

(b) Model $C_{A, t o t a l}, C_{N}$, and $C_{m}$

Figure 10. Comparison of averaged CFD and test surface pressure coefficient as well as code-to-code comparisons of $C_{A, \text { total }}, C_{N}$, and $C_{m}$ as a function of time. Run 165, single nozzle, $C_{T} 2$. 


\section{V.C. Run 262, Triple Nozzle, $C_{T} 3, \phi 0^{\circ}$}

Run 262 showed random unsteadiness in the plume to freestream interaction. The unsteadiness was shown in the bow shock behavior, which oscillated to different degrees throughout the testing time window. Qualitatively, the FUN3D and OVERFLOW results most resemble the test Schlieren; however, that did not guarantee a good comparison in surface pressure. In the DPLR simulated shadowgraph images, the skewness in the area just aft of the model shoulder is due to grid effects of an overset region and a drop in resolution (see Figure 4).

The level of unsteadiness for each code is apparent in the force and moment plots seen in Figure 14. Large deviation is seen in the total axial force between the codes. The thrust component of the coefficient overpowers the aerodynamic effects, and as such, small deviations in properly simulating the thrust coefficient become apparent. The computed $C_{T}$ from the test was 2.937, which is closely simulated by FUN3D (2.99) and OVERFLOW (2.975), DPLR simulated a larger $C_{T}$ (3.109).

For the surface pressure, large deviations between the codes are seen at the model nose. None of the codes properly predict the pressure at the nose for $\alpha=0^{\circ}$, OVERFLOW comes close for $\alpha=12^{\circ}$, and better agreement is seen for $\alpha=16^{\circ}$. Differences in simulated jet expansion and jet-to-jet interactions may be the source of these deviations.

For both $\alpha=0^{\circ}$ and $\alpha=12^{\circ}$, FUN3D overpredicts the pressure for $r / R<0.4$ and for the entire model face for $\alpha=12^{\circ}$. The rise in pressure near the nozzle at $r / R \sim 0.35$ is captured in behavior and value by OVERFLOW, and by behavior for FUN3D. Large differences are seen on the windward side of the model face near the shoulder at non-zero angles of attack. In that region, DPLR and FUN3D properly predict the pressure for $\alpha=16^{\circ}$ with OVERFLOW overpredicting. At $\alpha=12^{\circ}$ a different trend is seen with OVERFLOW giving the best prediction of the three codes. On the model side-body, DPLR is consistently higher in average pressure than FUN3D and OVERFLOW with varying levels of agreeance with tunnel data for all codes.

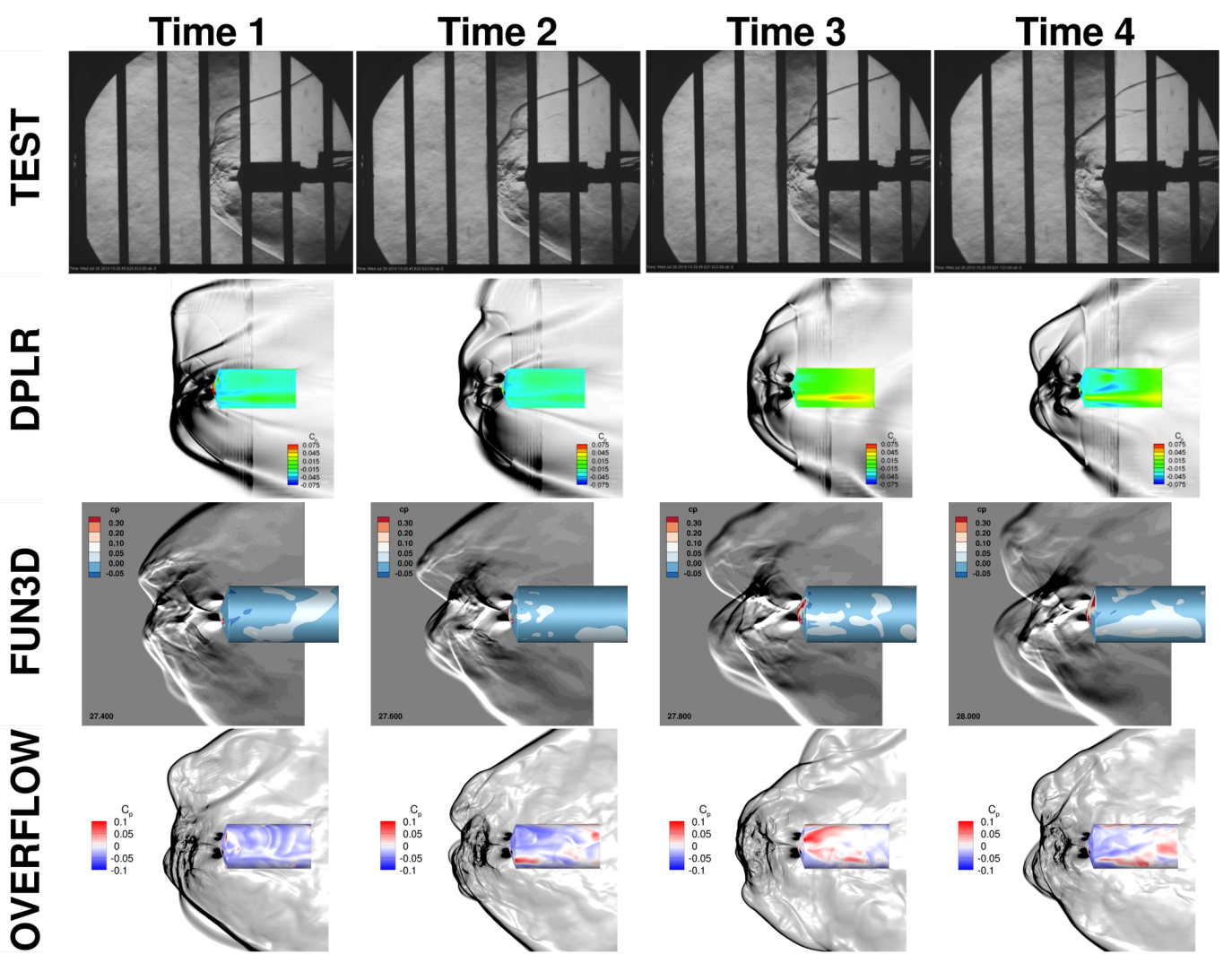

Figure 11. Flow visualizations of run 262, $\alpha 0^{\circ}, \phi 0^{\circ}$, triple nozzle, $C_{T} 3$. 

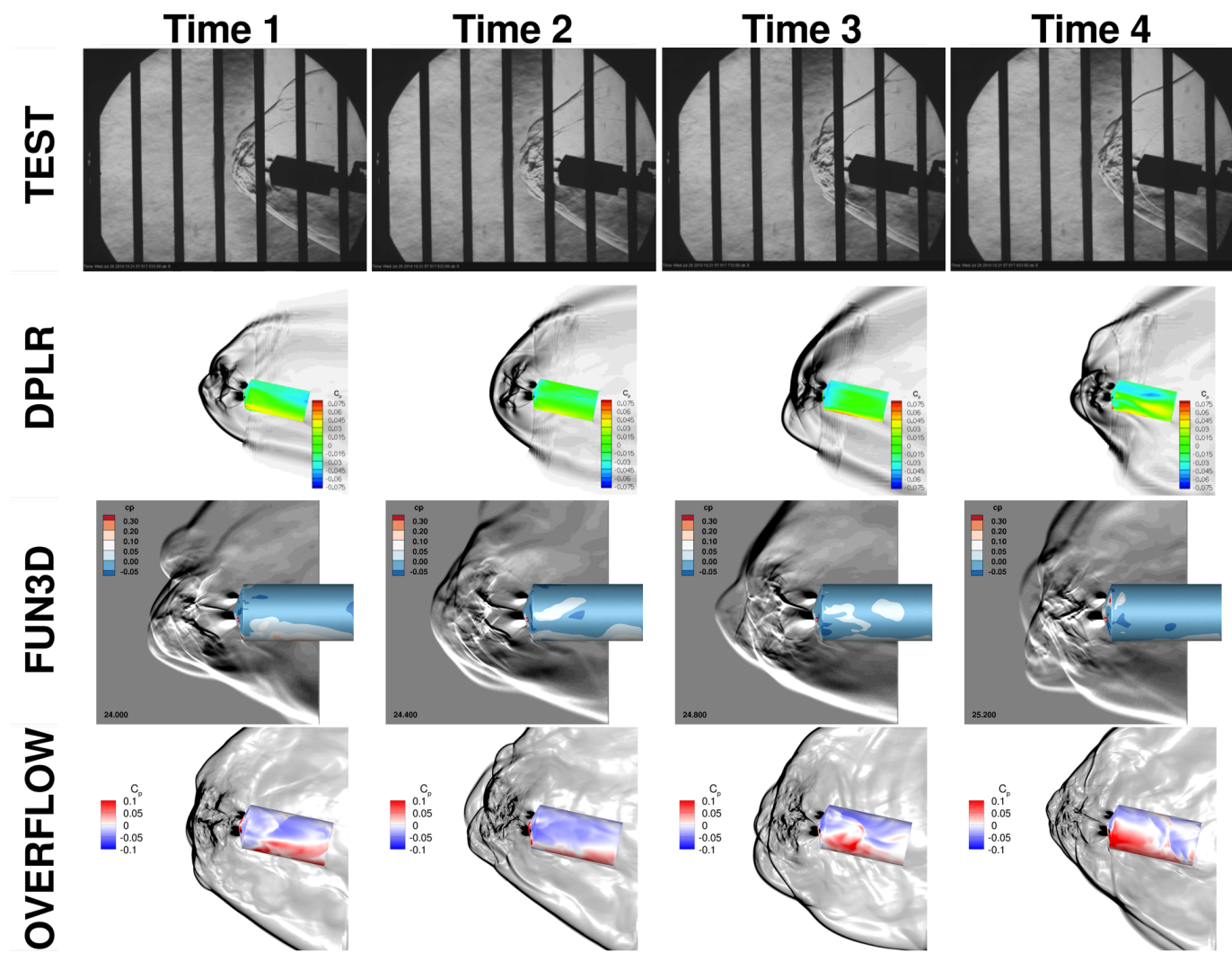

Figure 12. Flow visualizations of run $262, \alpha 12^{\circ}, \phi 0^{\circ}$, triple nozzle, $C_{T} 3$.
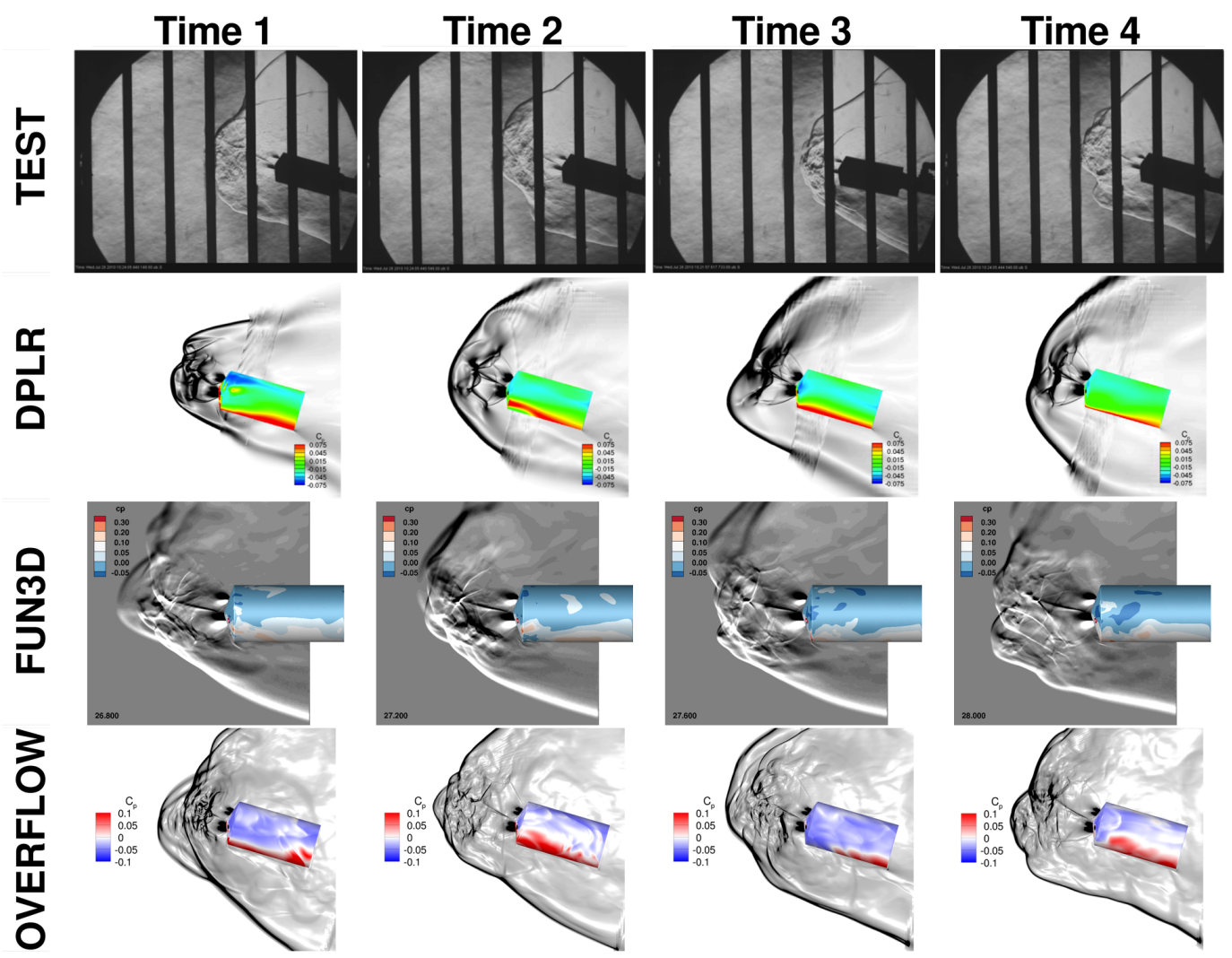

Figure 13. Flow visualizations of run $262, \alpha 16^{\circ}, \phi 0^{\circ}$, triple nozzle, $C_{T} 3$. 

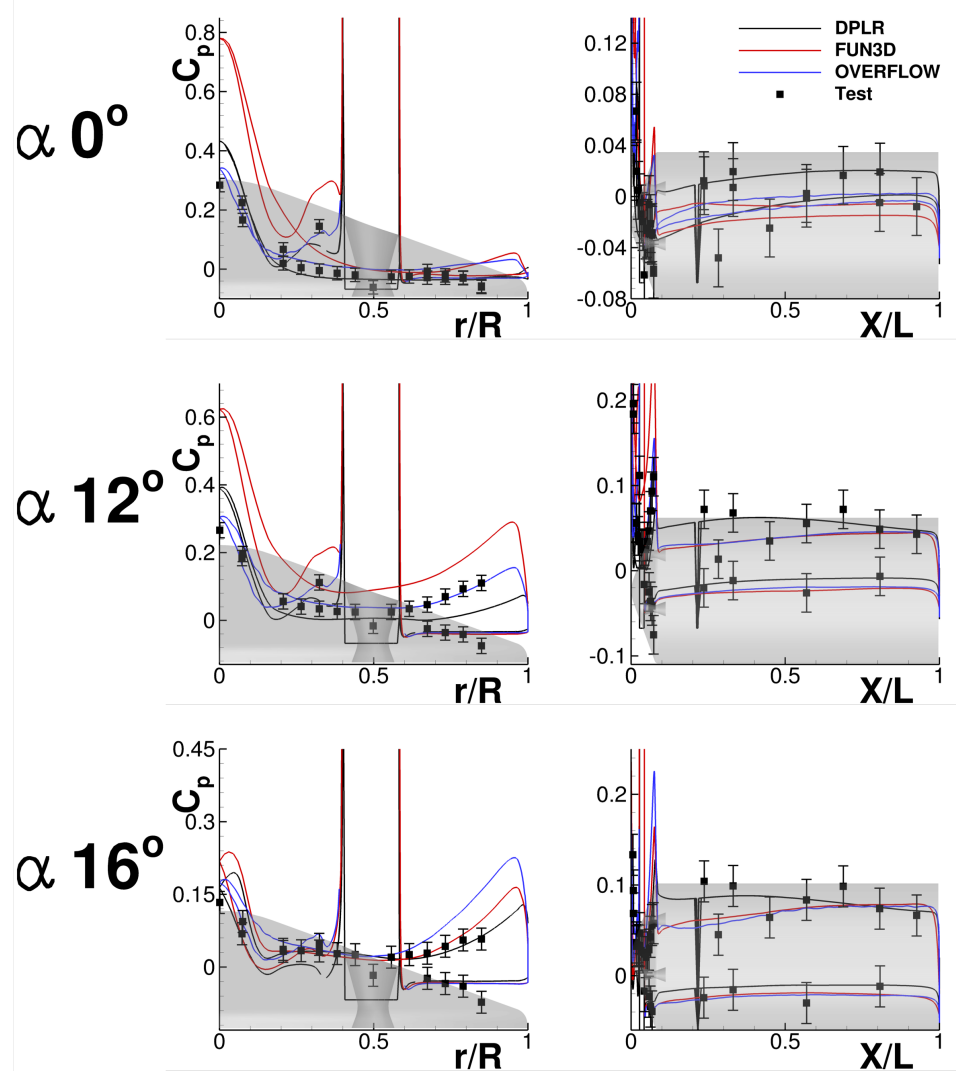

(a) Model surface $C_{P}$
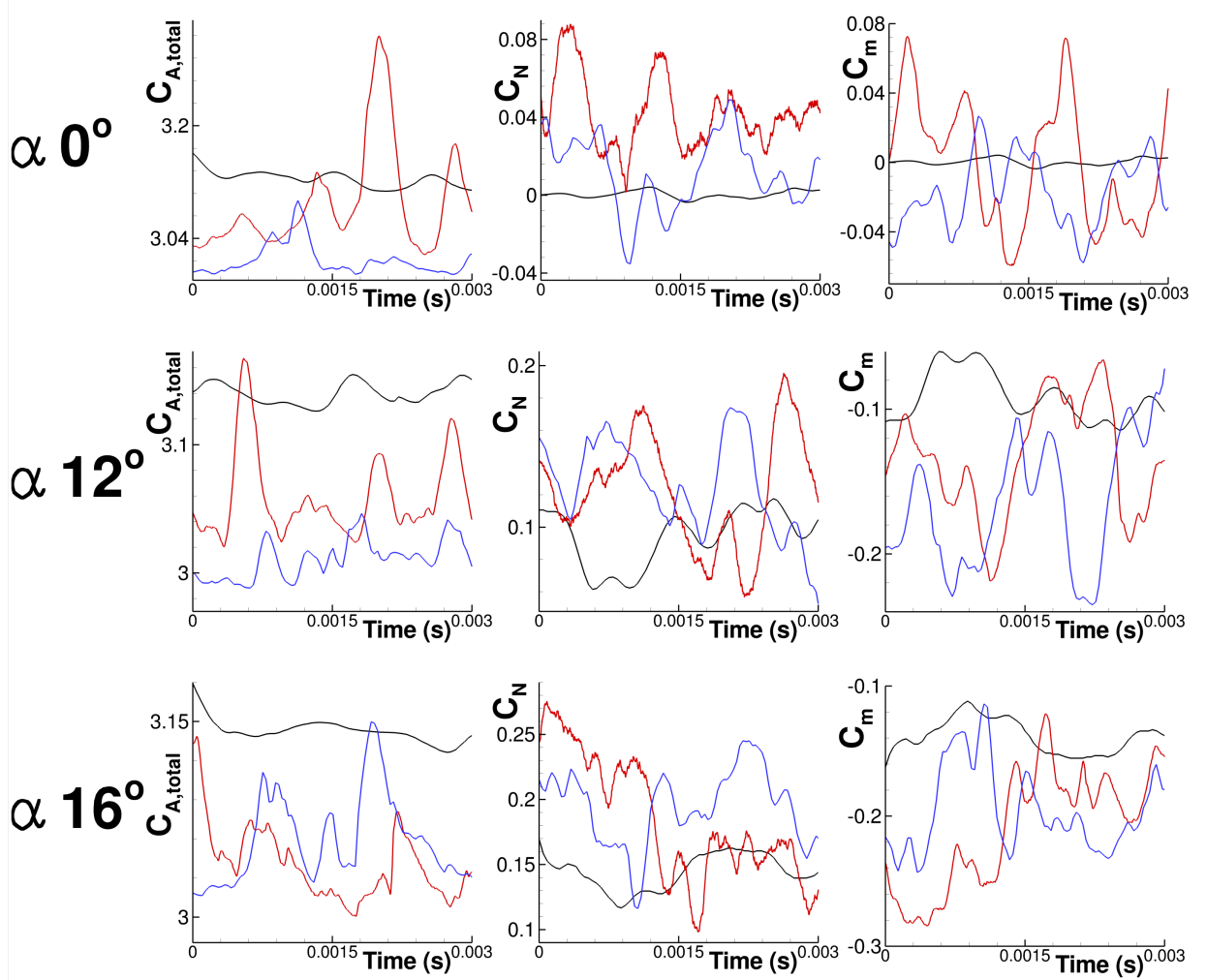

(b) Model $C_{A, \text { total }}, C_{N}$, and $C_{m}$

Figure 14. Comparison of averaged CFD and test surface pressure coefficient as well as code-to-code comparisons of $C_{A, \text { total }}, C_{N}$, and $C_{m}$ as a function of time. Run 262 , triple nozzle, $C_{T} 3, \phi 0^{\circ}$. 


\section{V.D. Run 263, Triple Nozzle, $C_{T} 3, \phi 180^{\circ}$}

Run 263 differs from run 262 only in roll angle, run 263 having the nozzle which lays in the symmetry plane facing windward for non-zero angles of attack. Little difference from run 262 was seen or expected at $\alpha=0^{\circ}$. However, for $\alpha=12^{\circ}$ and $\alpha=16^{\circ}$, run 263 displayed steadier behavior than run 262. The windward side of the flowfield demonstrated a firmly placed bow shock, and little differences were seen in the barrel plume or termination shocks. Shedding from the jets did occur on the leeward side which pushed the bow shock in that area back in a semi-oscillatory manner. The shedding was then pushed downstream, which for the most part did not effect the model surface.

The steadier flow behavior for non-zero angles of attack was captured the best by FUN3D. DPLR and OVERFLOW showed unsteady behaviors similar to run 262.

Pressure at the nose is again a weak point in the CFD simulations. Large deviation is seen between the codes and none of the codes properly match the tunnel data. The pressure on the model face for $\alpha=0^{\circ}$ was overpredicted by FUN3D. For the non-zero angles of attack on the model side shell, the DPLR results compare the best with tunnel data on the windward side while FUN3D and OVERFLOW underpredict for $\alpha=12^{\circ}$, and OVERFLOW underpredicts for $\alpha=16^{\circ}$.

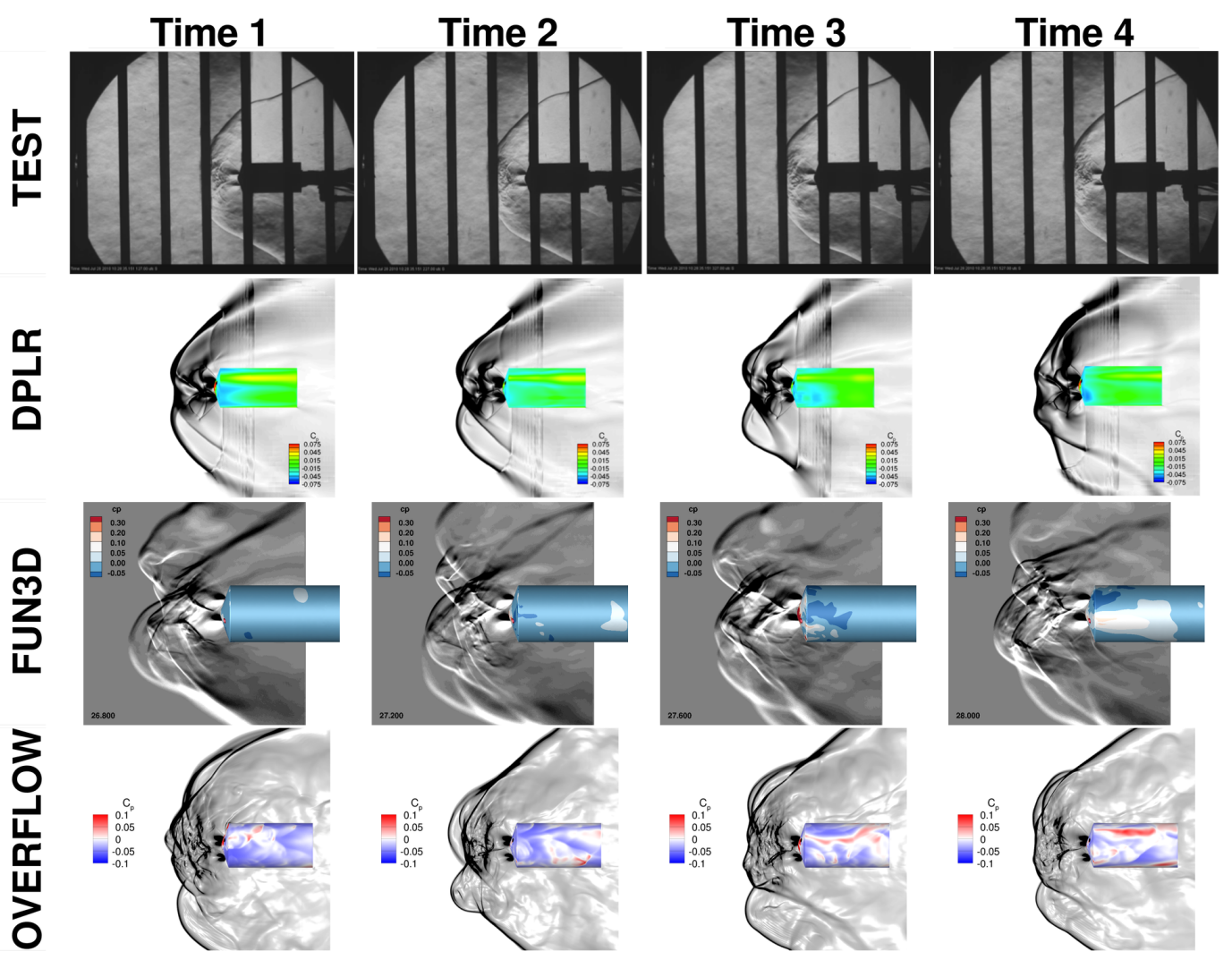

Figure 15. Flow visualizations of run $263, \alpha 0^{\circ}, \phi 180^{\circ}$, triple nozzle, $C_{T} 3$. 

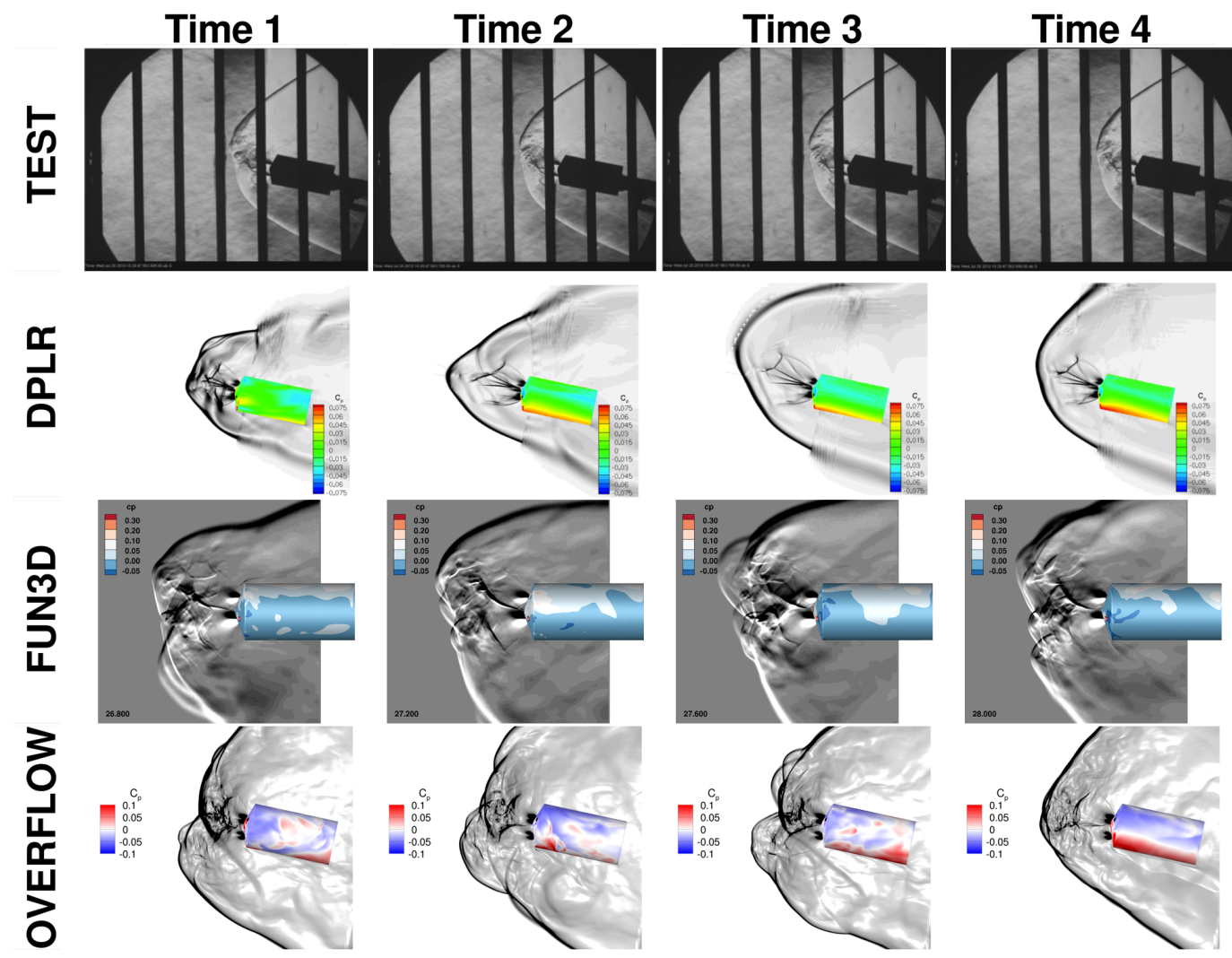

Figure 16. Flow visualizations of run $263, \alpha 12^{\circ}, \phi 180^{\circ}$, triple nozzle, $C_{T} 3$.
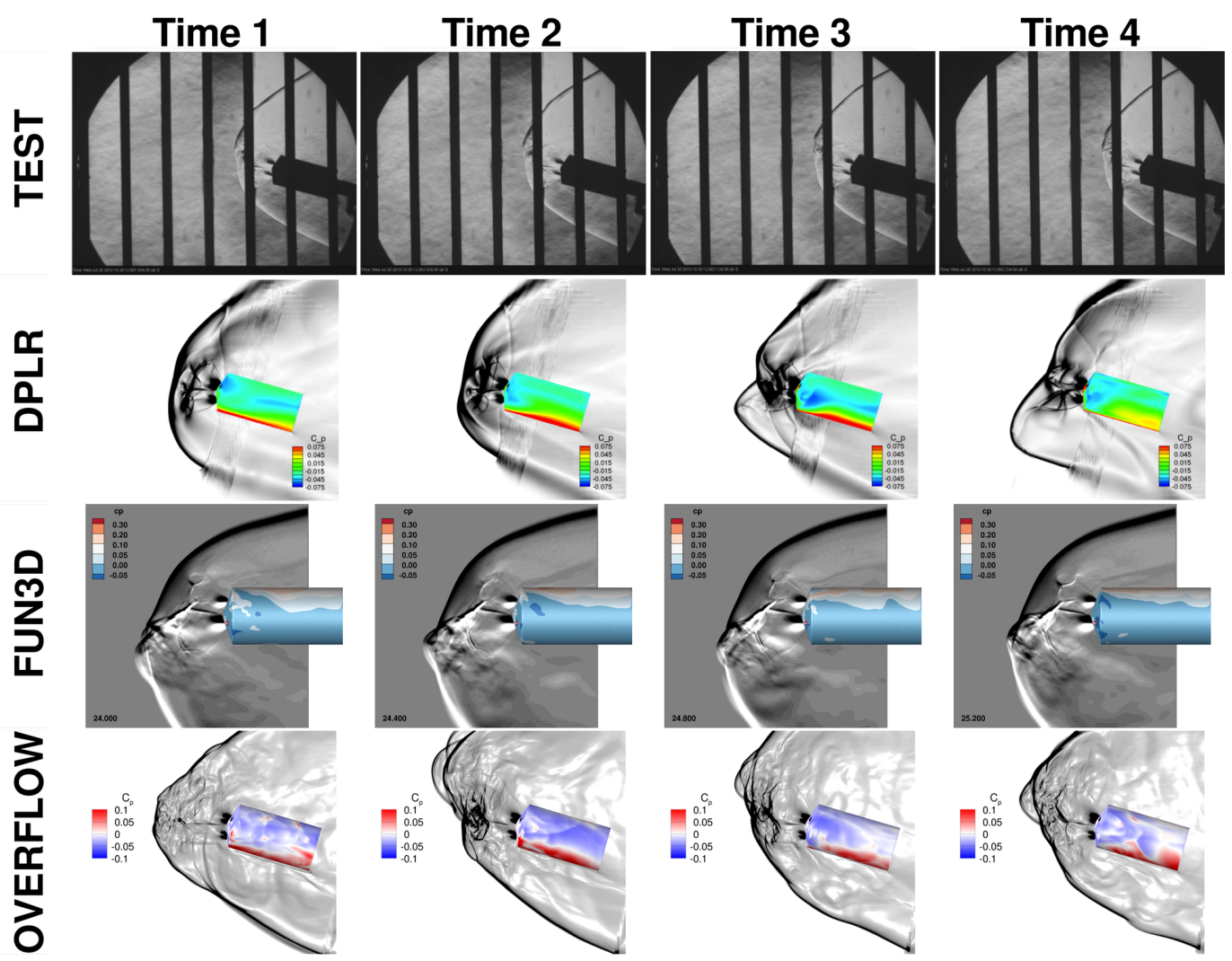

Figure 17. Flow visualizations of run $263, \alpha 16^{\circ}, \phi 180^{\circ}$, triple nozzle, $C_{T} 3$. 

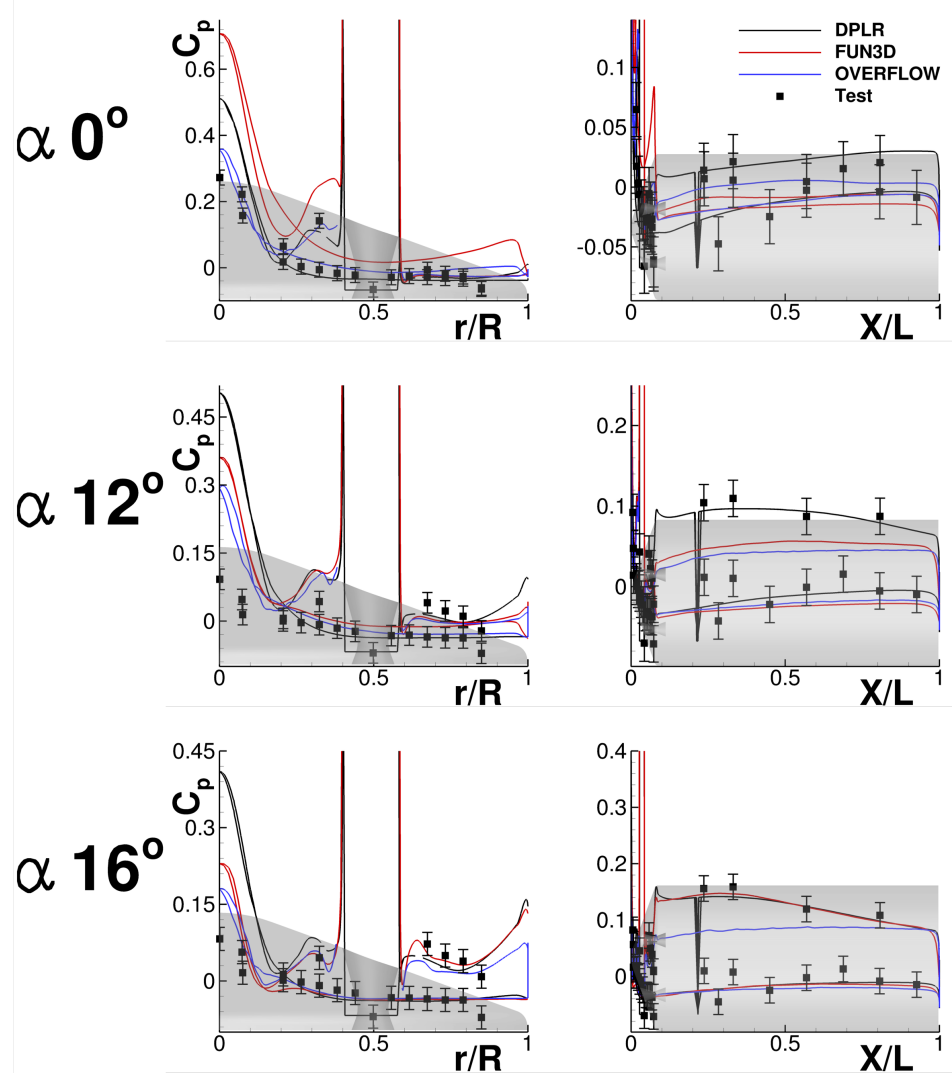

(a) Model surface $C_{P}$
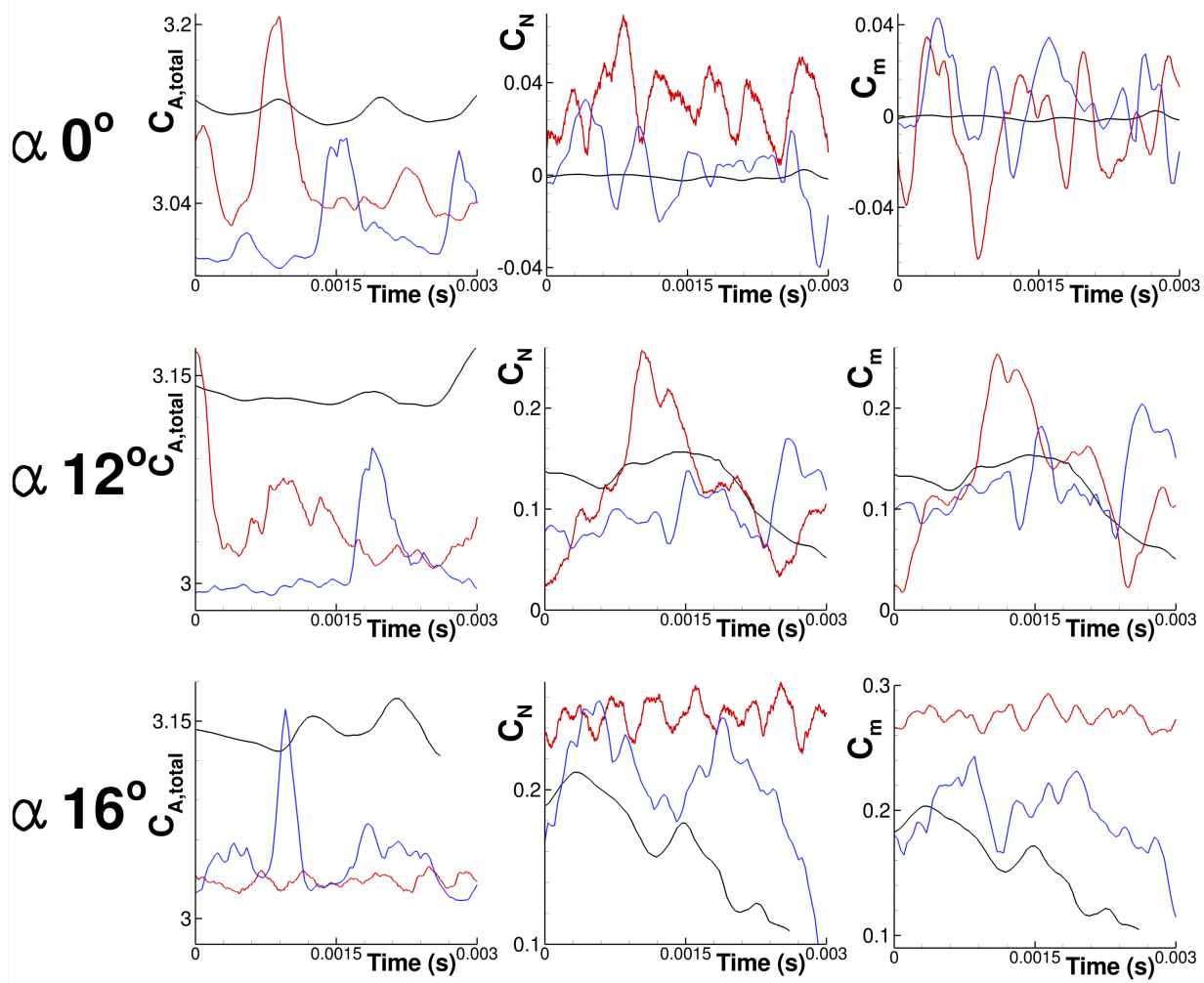

(b) Model $C_{A, t o t a l}, C_{N}$, and $C_{m}$

Figure 18. Comparison of averaged CFD and test surface pressure coefficient as well as code-to-code comparisons of $C_{A, \text { total }}, C_{N}$, and $C_{m}$ as a function of time. Run 263 , triple nozzle, $C_{T} 3, \phi 180^{\circ}$. 


\section{V.E. Run 307, Quad Nozzle, $C_{T} 2, \phi 0^{\circ}$}

Run 307 at $\alpha=0^{\circ}$ demonstrated a steadier mode than seen in any of the triple nozzle cases. The flow was similar to run $165 \alpha=0^{\circ}$ in that periodic oscillations of the triple points occurred and the bow shock is in a steadier state relatively close to the body. However, the flow physics are more complex now with the added plume to plume interactions. For $\alpha=12^{\circ}$ and $\alpha=20^{\circ}$, similar chaotic unsteadiness to run 262 is seen with fluctuations in the bow shock.

For $\alpha=0^{\circ}$, FUN3D and OVERFLOW properly simulate the steadier flowfield with the short bow shock standoff distance. The DPLR simulation shows behavior of a larger bow shock standoff distance as it approaches a steady state. The bow shock standoff distance does not seem to influence the surface pressure, however, since the plume structure is large enough to block oncoming freestream flow from the model. The pressure on the model is low, and all codes fall within experimental uncertainties with the exception of OVERFLOW below the center nozzle.

For $\alpha=12^{\circ}$ and $\alpha=20^{\circ}$, all codes predict a higher level of unsteadiness, FUN3D picking up the most fluctuations For the most part, all codes predict $C_{P}$ well on the side of the model, except OVERFLOW underpredicts aft of the shoulder for $\alpha=12^{\circ}$, and FUN3D underpredicts aft of the shoulder for $\alpha=20^{\circ}$. On the model face, all three codes predict the leeward $C_{P}$ well but larger deviations are seen on the windward side. On the windward side, OVERFLOW underpredicts for $\alpha=12^{\circ}$ underpredict for $\alpha=20^{\circ}$.

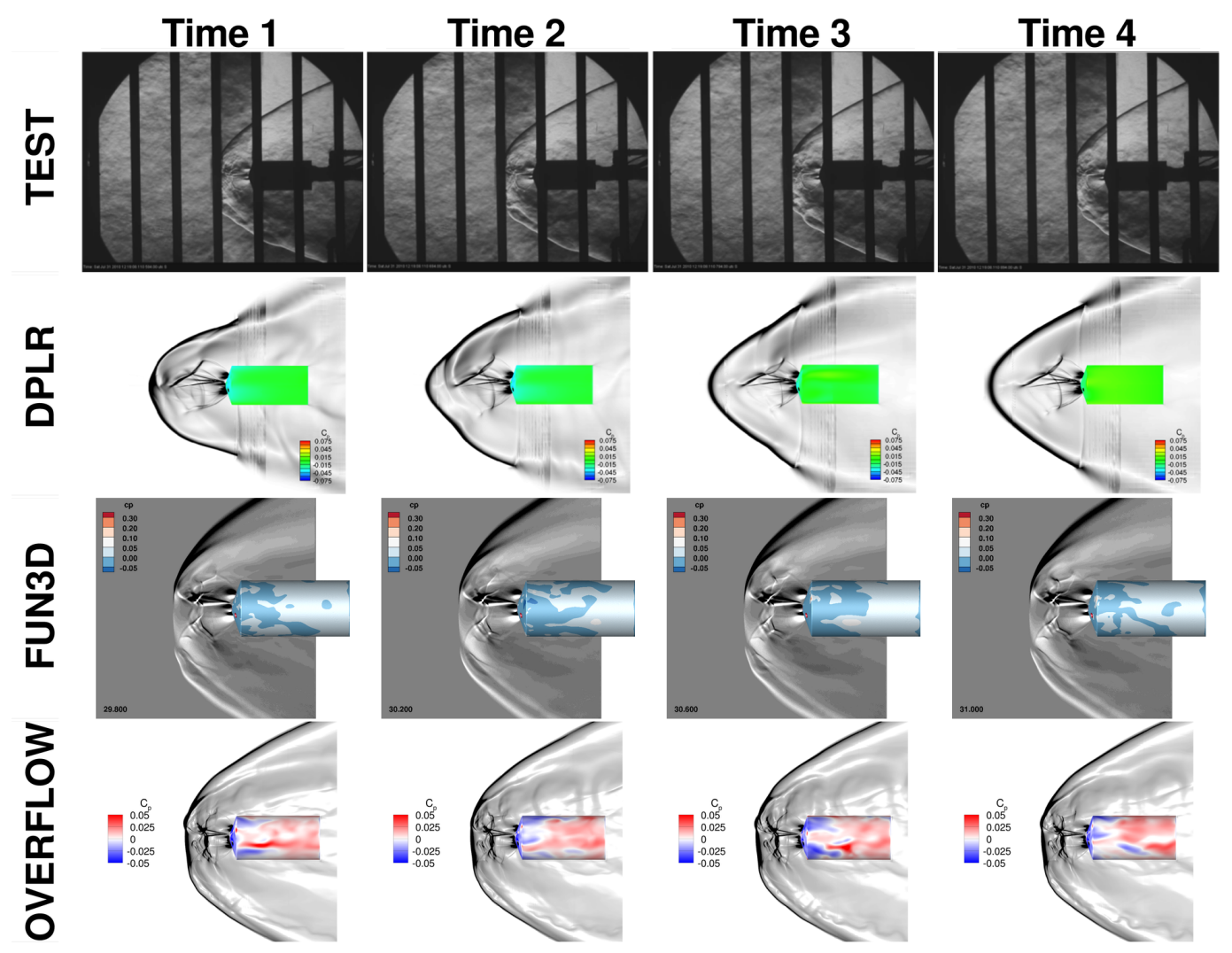

Figure 19. Flow visualizations of run $307, \alpha 0^{\circ}, \phi 0^{\circ}$, quad nozzle, $C_{T} 2$. 

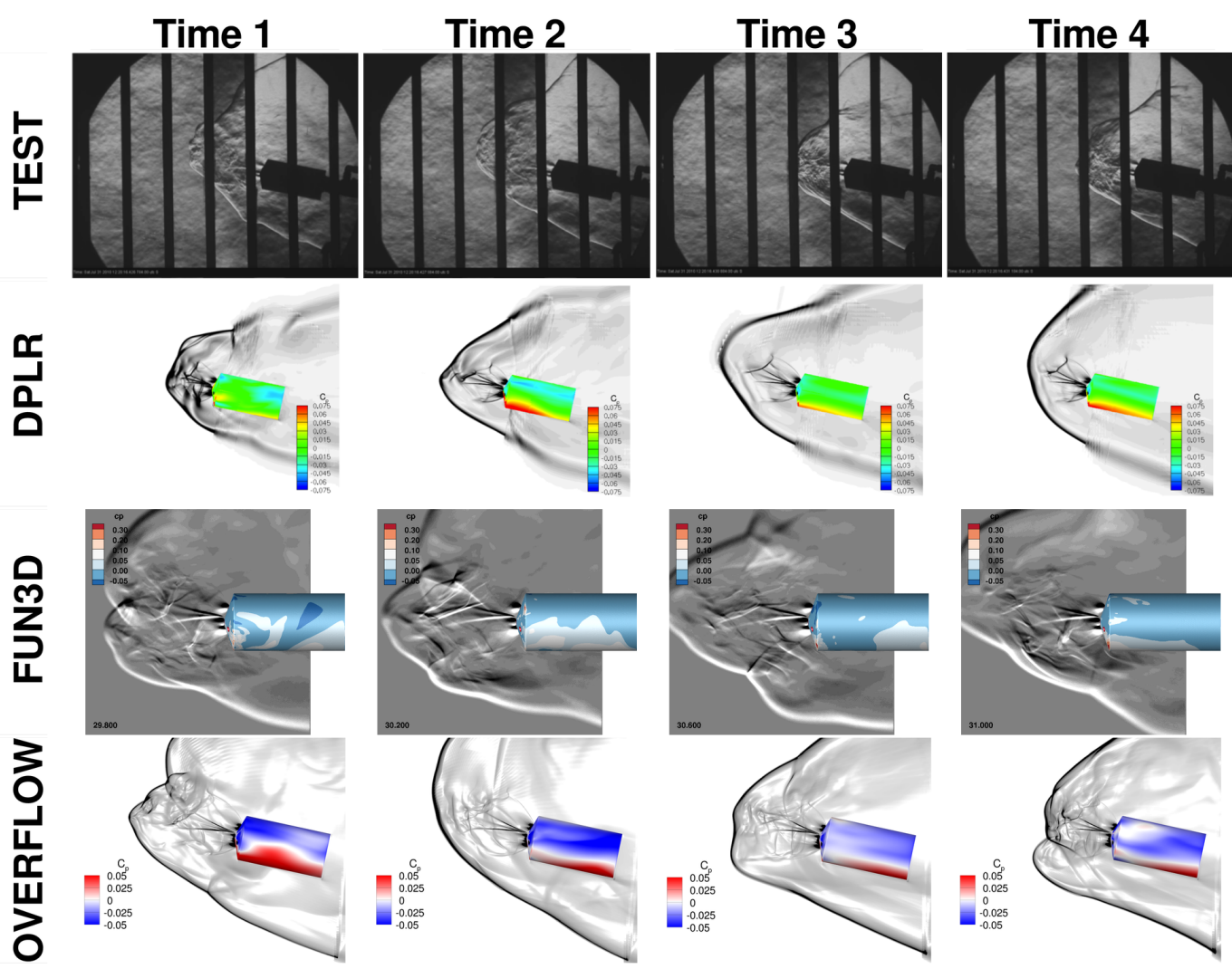

Figure 20. Flow visualizations of run $307, \alpha 12^{\circ}, \phi 0^{\circ}$, quad nozzle, $C_{T} 2$.
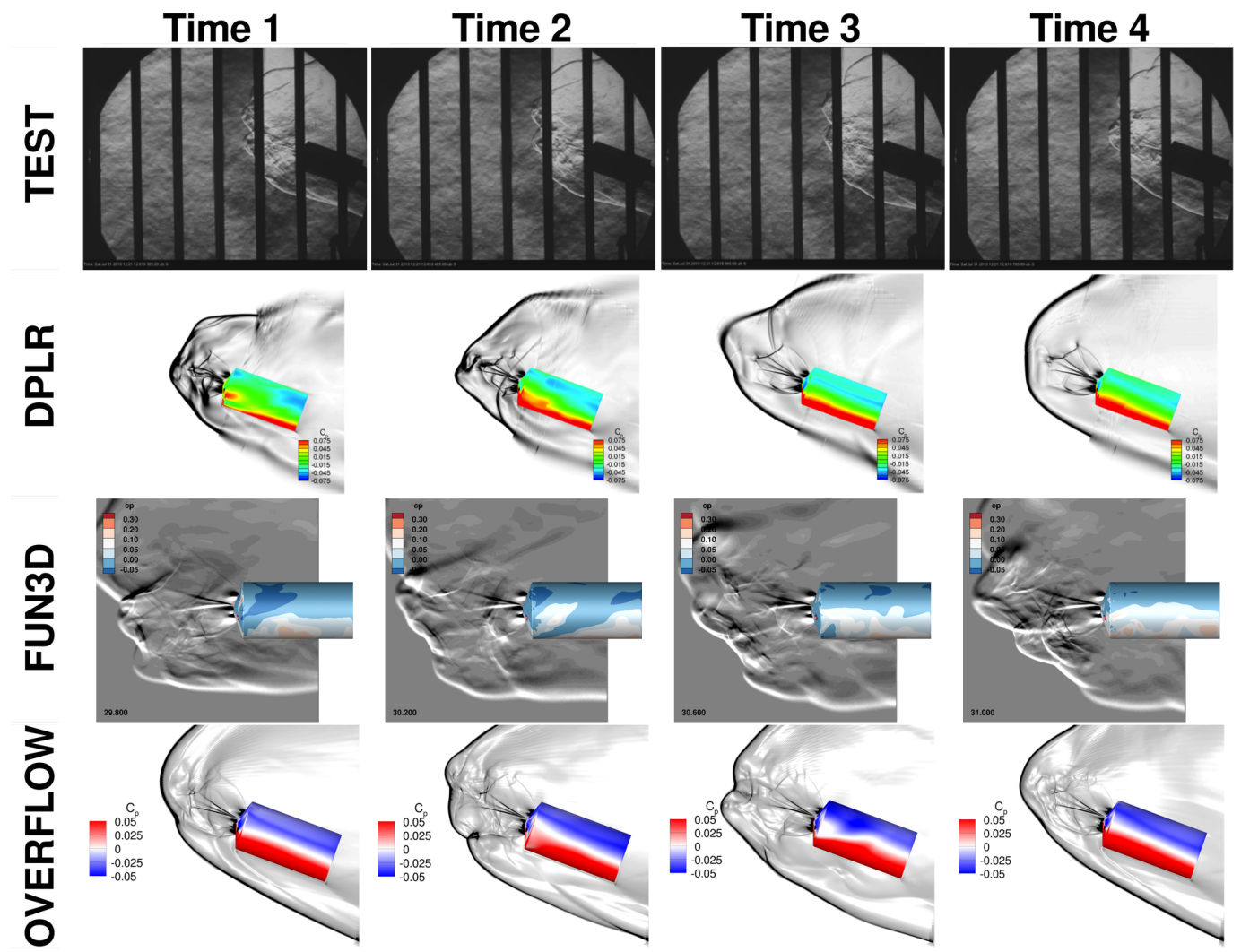

Figure 21. Flow visualizations of run $307, \alpha 20^{\circ}, \phi 0^{\circ}$, quad nozzle, $C_{T} 2$. 

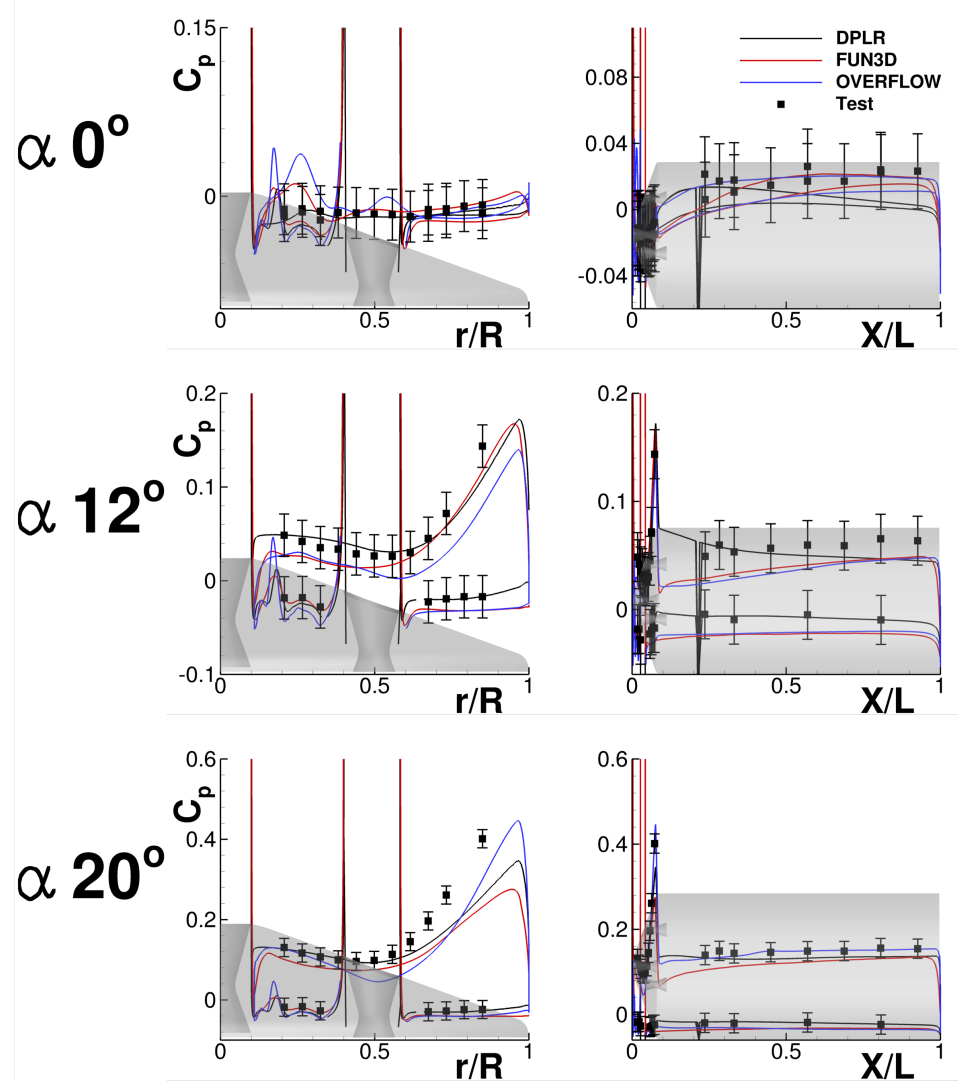

(a) Model surface $C_{P}$
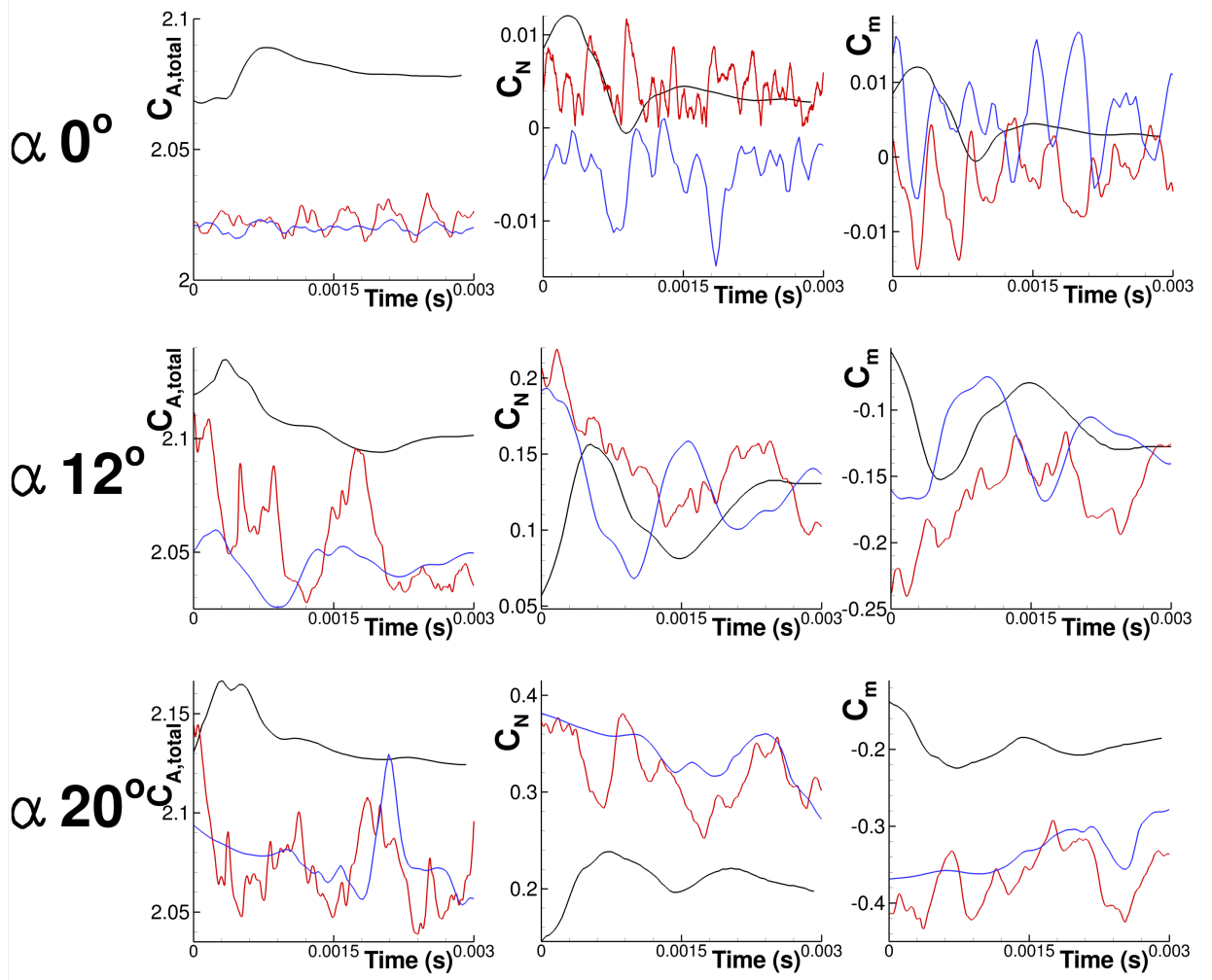

(b) Model $C_{A, \text { total }}, C_{N}$, and $C_{m}$

Figure 22. Comparison of averaged CFD and test surface pressure coefficient as well as code-to-code comparisons of $C_{A, t o t a l}, C_{N}$, and $C_{m}$ as a function of time. Run 307 , quad nozzle, $C_{T} 2, \phi 0^{\circ}$. 


\section{V.F. Run 311, Quad Nozzle, $C_{T} 2, \phi 180^{\circ}$}

The same steadier behavior seen in run 307 at $\alpha=0^{\circ}$ was seen in run 311 at $\alpha=0^{\circ}$, as expected. This behavior was properly simulated by DPLR and FUN3D. OVERFLOW predicted an unsteady bow shock behavior that oscillated between near correct and very large standoff distances. Even with the differences in behavior, the $C_{P}$ on the model face was similar to that seen for run 307 at $\alpha=0^{\circ}$. On the side of the model OVERFLOW predicted lower pressure than DPLR and FUN3D, but were mostly still inside the tunnel uncertainty.

For $\alpha=12^{\circ}$, a steadier mode was observed where the windward bow shock was somewhat stable, and the leeward bow shock showed an unsteady oscillatory shedding. This behavior was predicted most accurately by DPLR. Toward the end of the test Schlieren video, this mode shifted to more like the behavior seen in the OVERFLOW results.

An even steadier mode was observed in the $\alpha=20^{\circ}$ than the $\alpha=12^{\circ}$ case. FUN3D and OVERFLOW capture this mode while the DPLR results were unsteady. All codes predict the surface $C_{P}$ well except for on the windward face between the peripheral nozzle and shoulder, and just aft of the shoulder on the windward side.

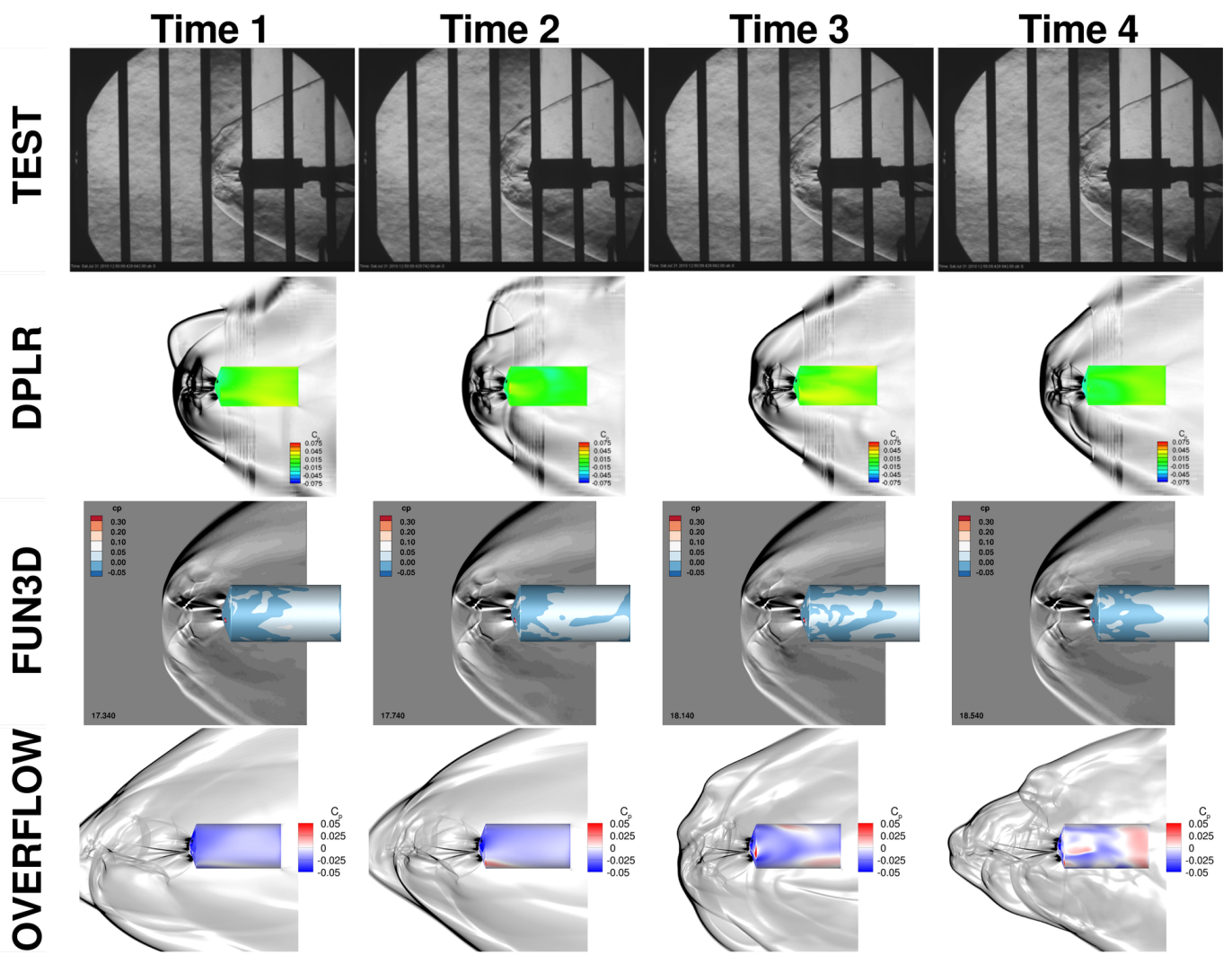

Figure 23. Flow visualizations of run 311, $\alpha 0^{\circ}, \phi 180^{\circ}$, quad nozzle, $C_{T} 2$. 

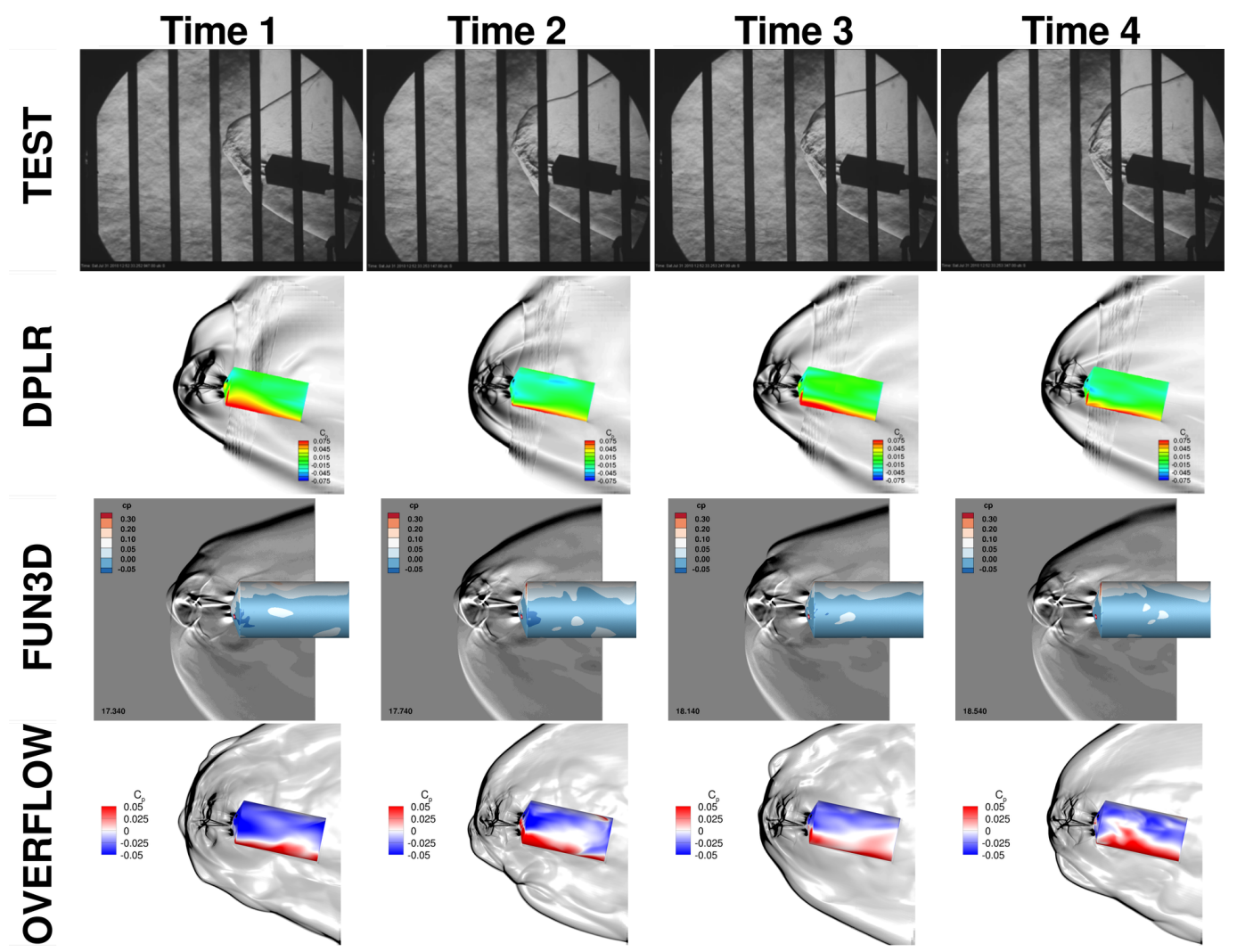

Figure 24. Flow visualizations of run $311, \alpha 12^{\circ}, \phi 180^{\circ}$, quad nozzle, $C_{T} 2$.
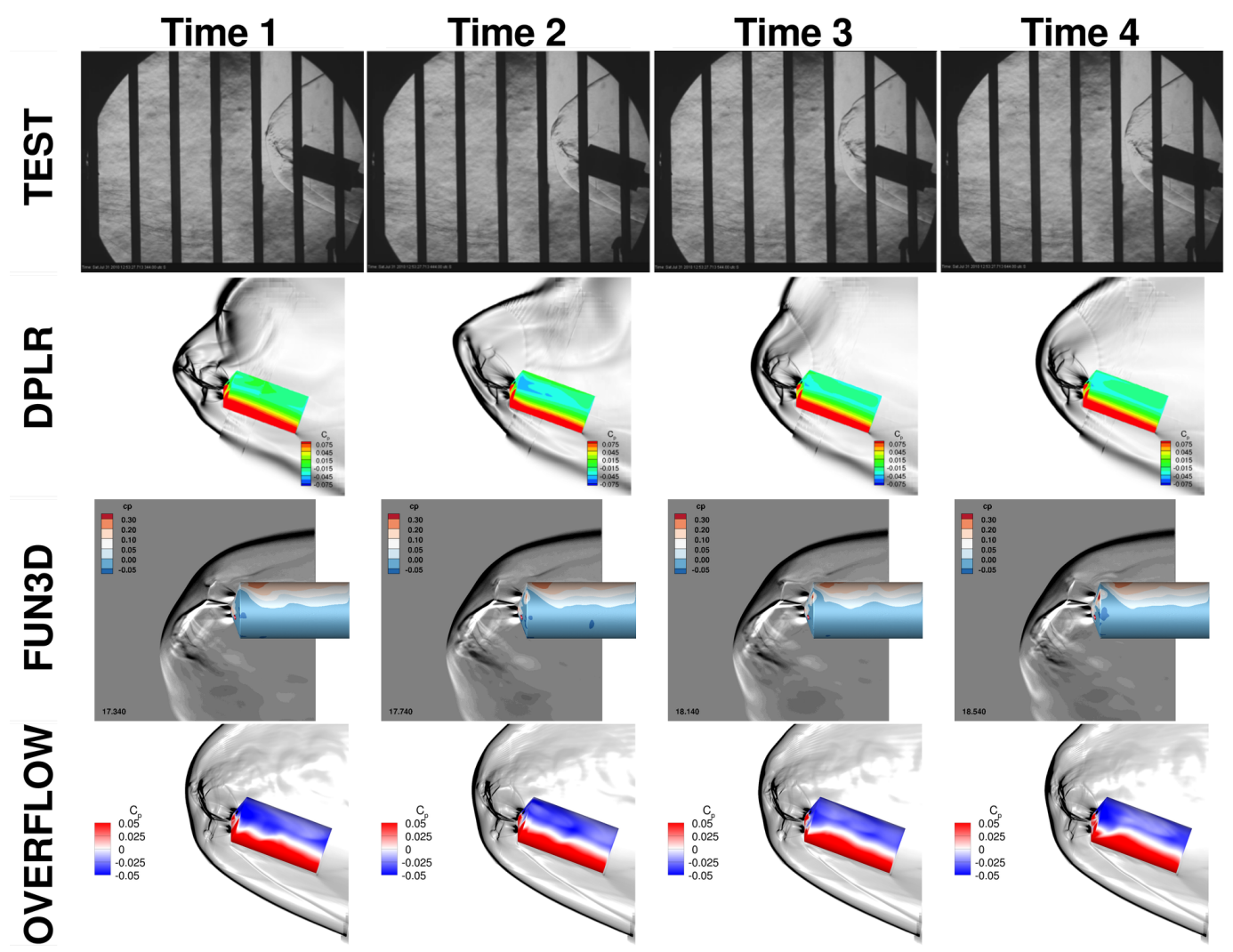

Figure 25. Flow visualizations of run $311, \alpha 20^{\circ}, \phi 180^{\circ}$, quad nozzle, $C_{T} 2$. 

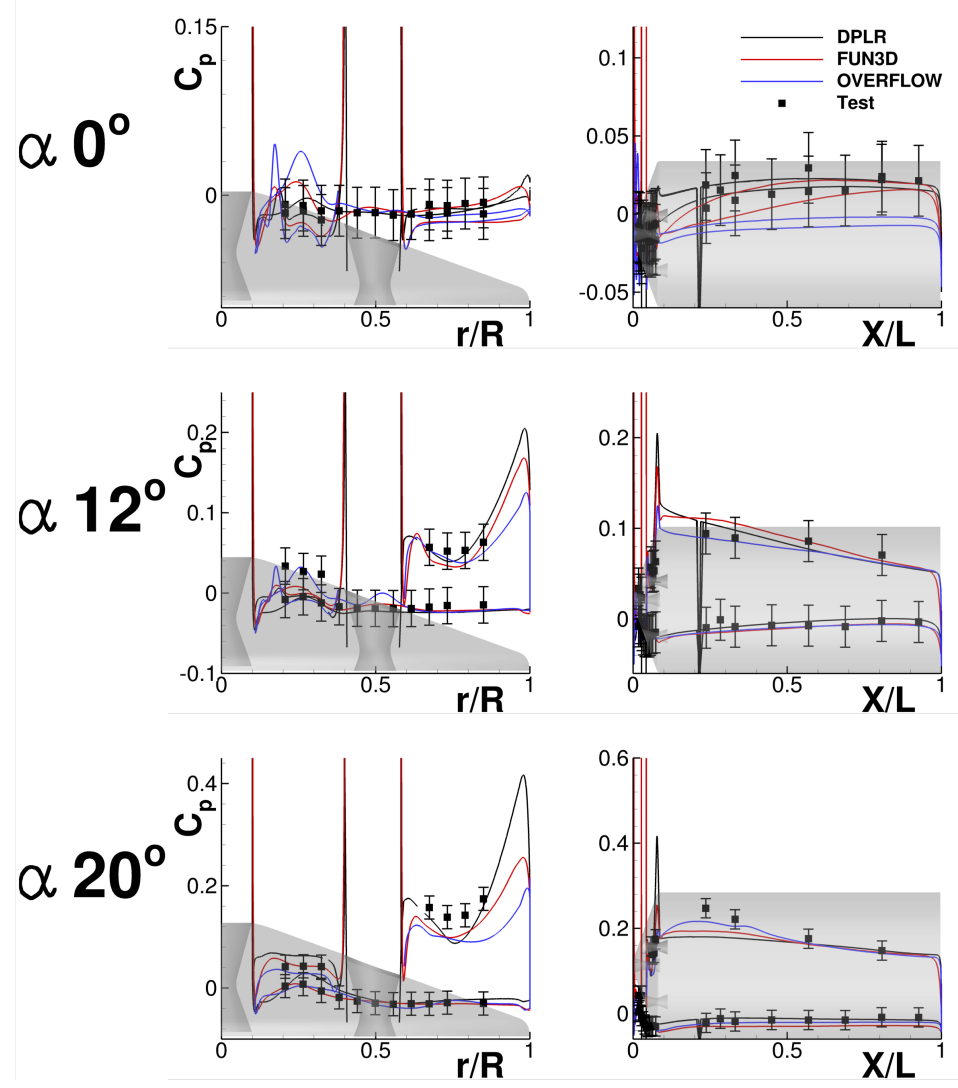

(a) Model surface $C_{P}$
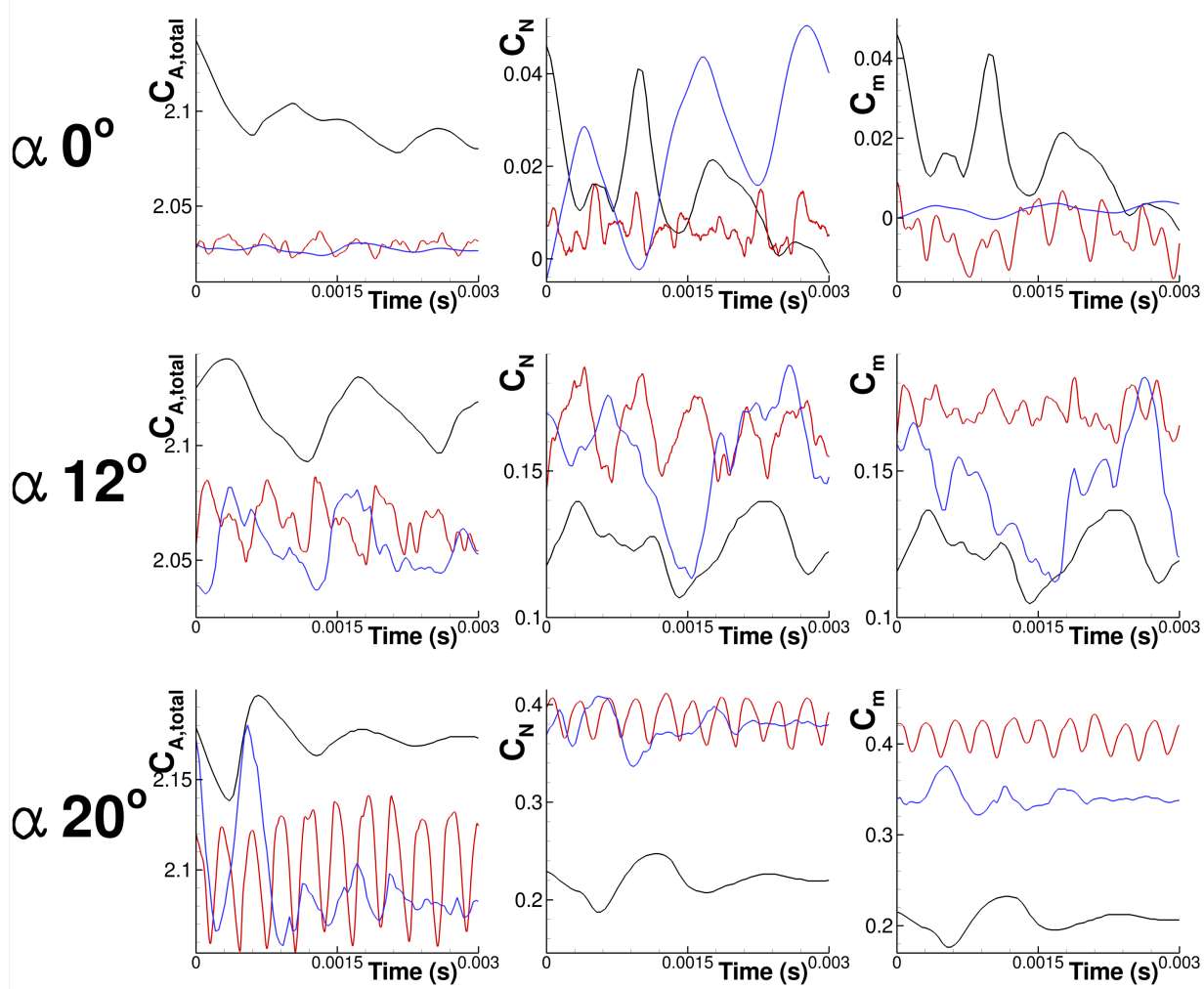

(b) Model $C_{A, \text { total }}, C_{N}$, and $C_{m}$

Figure 26. Comparison of averaged CFD and test surface pressure coefficient as well as code-to-code comparisons of $C_{A, \text { total }}, C_{N}$, and $C_{m}$ as a function of time. Run 311, quad nozzle, $C_{T} 2, \phi 180^{\circ}$. 


\section{Discussion of Results}

One of the largest differences in the code-to-code comparison was the level of unsteadiness predicted by each solver. DPLR, FUN3D, and OVERFLOW all used the SST turbulence model, but the implementation was slightly different for all. DPLR used the vorticity based production term, while OVERFLOW used the strain-based production term with the realizability constraint. OVERFLOW used DES with SST as the submodel for the single and triple nozzle cases, and RANS SST for the zero and quad nozzle cases. FUN3D used DES with SA as the submodel. Each of these turbulence models generates different levels of eddy viscosity, which may add dissipation to the solutions making them more steady. Generally speaking, the RANS models were more steady than the DES and the voriticity based SST models were more steady than the strain based with realizability constraint, although grid resolution and code implementation may also significantly contribute to those trends.

Grid resolution is also another difference among the flow solvers. Even though refinement for all grids is focused on the plume region, differences in spacing and topology do exist (see reference [9]). The level of unsteadiness is influenced by the level of dissipation, which can be increased by the coarseness of the grid.

The ability to properly capture the unsteady effects had varying effect on matching test averaged surface $C_{P}$. Solving the simulations time-accurately took large computing resources to obtain an average. It was shown that in some circumstances a steady state solution compared as well as a time-accurate one (for example, run $262 \alpha=16^{\circ}$ or run $311 \alpha=12^{\circ}$ ). Other cases, it seemed to matter that unsteady effects were captured (for example run $165 \alpha=0^{\circ}, \alpha=12^{\circ}$ or run $262 \alpha=12^{\circ}$ ). No specific trend was established meaning a case by case inspection would be required. Since that is the case, to be able to predict an SRP flowfield where test or flight data is not available, a time-accurate approach would be required since it would not be possible to know if a steady state solution would be sufficient.

Obtaining a proper average from such an unsteady flowfield was an issue with the CFD results. A small time step was required to resolve the high frequency unsteadiness, and yet a large amount of time is needed to define an average. The periodic unsteady behavior seen in run 165 at $\alpha=0^{\circ}$ was more conducive to calculating a proper average, but for other cases, the unsteadiness was random, and no periodicity was noted. It may have been possible for the CFD to resolve a certain section of the unsteady behavior and obtain a converged average, but still not cover the entire 2.5 seconds of the test data acquisition window, and not obtain the same average as the pressure taps.

For the wind tunnel, the pressure taps (not including the high frequency gauges) took 25 or 75 readings over 2.5 seconds, giving rates of 10 or 30 readings per second. For the CFD results, total run times were under 0.05 seconds with thousands of data points for averaging. The wind tunnel sample interval ( 0.1 or 0.033 seconds) is on the order or greater than the total CFD run times. This means flowfield variations with time scales longer than 0.1 seconds would be averaged out in the wind tunnel data but totally missed in the CFD. Also, flowfield variations less than the tunnel sample interval were captured and averaged by the CFD but totally missed by the wind tunnel data.

With the inherent unsteadiness of the flowfield, vehicle stability becomes a concern. It is important to realize that the measured unsteadiness in the surface tap readings have a small contribution to the total axial force. Figure 27 shows a bar chart depicting the contributions of aerodynamics and thrust to the overall axial force coefficient. In most cases, the surface aerodynamic forces contribute less than $5 \%$. This should result in the surface pressures creating an even smaller percentage of the total axial force. Also, the required flight thrust coefficients will be much higher $(\sim 10 \mathrm{~s})$ than those achieved in the test. Thrust coefficients this large were not obtained in this test due to tunnel interference. A couple runs were made for the triple nozzle configuration at $\alpha=0^{\circ}$ with $C_{T}$ values as high as 6 . At this higher thrust coefficient, the flow was more steady as seen in Figure 28 and the contribution of aerodynamic effects to the total axial force was much less than for smaller thrust coefficients. Future plans of the project is to take the same 5 inch diameter model into the Ames 9'x7' Unitary Plan Wind Tunnel. With the larger test section, tunnel wall effects will be minimized and larger thrust coefficients will be possible. 


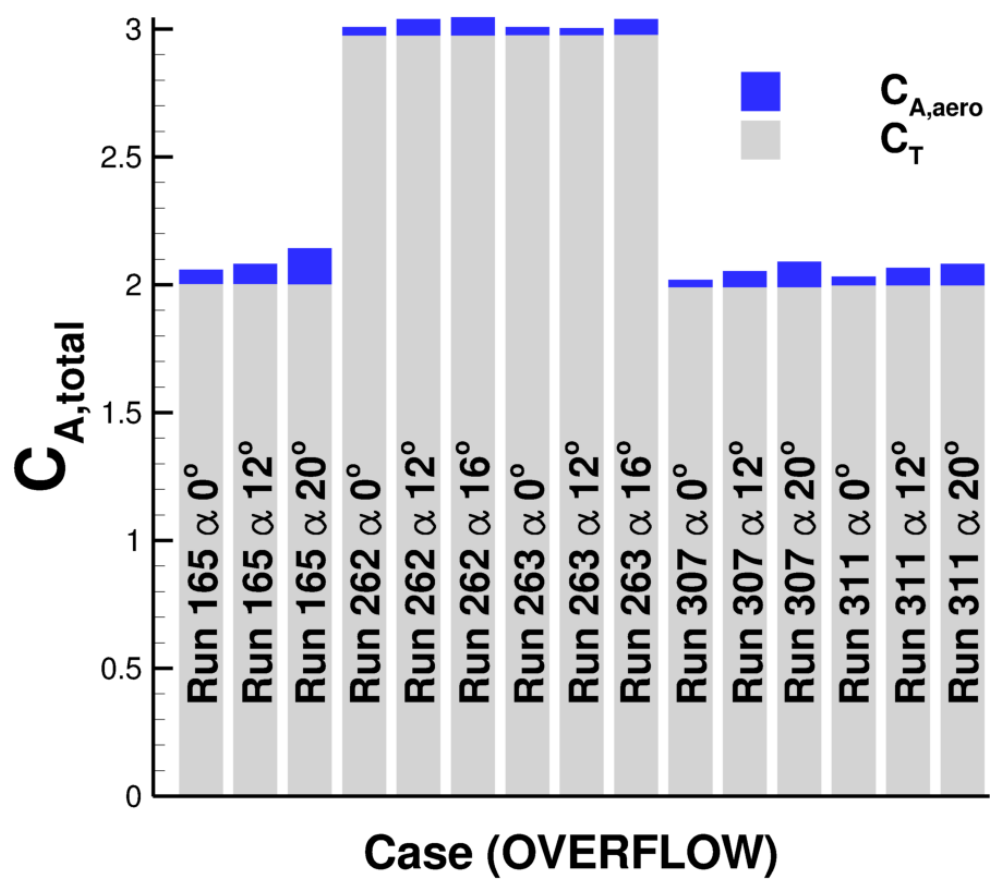

Figure 27. Contributions of aerodynamic surface forces and thrust to the total axial force coefficient.

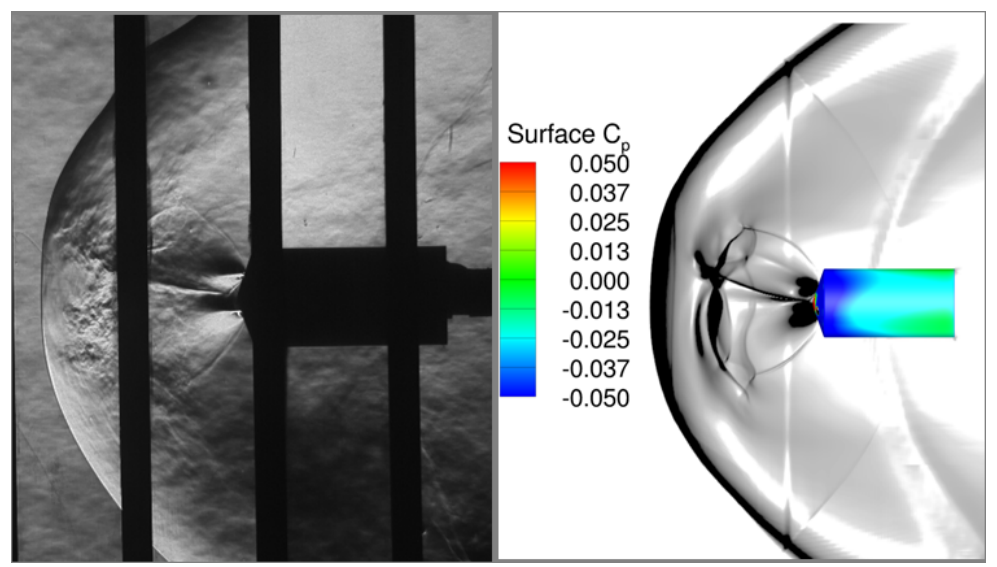

Figure 28. Wind tunnel Schlieren (left) and constructed Schlieren of OVERFLOW simulation (right) of the triple nozzle configuration at Mach 3.5 and $C_{T}=6$. This higher thrust coefficient demonstrated steadier behavior.

\section{Conclusions}

Computational fluid dynamics has taken a strong step towards validation for supersonic retropropulsion. Using four solvers, DPLR, FUN3D, and OVERFLOW, comparisons were made to test 1853 from the Langley supersonic Unitary Plan Wind Tunnel. Code-to-code and code-to-test comparisons are encouraging and possible error sources have been defined. An inherent unsteadiness was noted at the tested thrust coefficients, but it was noted that the flowfield is much steadier at higher thrust coefficients for the triple nozzle configuration.

\section{Acknowledgments}

Pieter G. Buning of NASA Langley Research Center, Hampton, Virginia, Phillip C. Stuart and Darby J. Vicker of NASA Johnson Space Center, Houston, Texas and Thomas M. Booth of Jacobs Technology, Houston, Texas provided valuable guidance on gridding and solver best practices for Overflow. William T. Jones of NASA Langley Research Center, Hampton, Virginia provided the GridEX/BatchEx unstructured 
grid generation framework and helped with its application to generate FUN3D grids. Todd R. White and Andrew J. Hyatt of ERC inc., Moffett Field, California helped develop DPLR best practices and provided overset gridding assistance for DPLR cases. David A. Saunders of ERC Inc., Moffett Field, California developed the code used for OVERFLOW and DPLR simulated Schlieren/shadowgraph visualizations.

The authors would like to acknowledge the support of the Exploration Technology Development and Demonstration (ETDD) Program, managed at NASA-Glenn Research Center. The work documented herein was performed as part of ETDDs Entry, Descent, and Landing (EDL) Technology Development Project, which is managed at NASA-Langley Research Center and supported by NASA-Ames Research Center, NASA-Johnson Space Center, and the Jet Propulsion Laboratory.

\section{References}

${ }^{1}$ Braun, R. D. and Manning, R. M., "Mars Exploration Entry, Descent, and Landing Challenges," Journal of Spacecraft and Rockets, Vol. 44, No. 2, 2007.

${ }^{2}$ Steinfeldt, B. A., Theisinger, J. E., Korzun, A. M., Clark, I. G., Grant, M. J., and Braun, R. T., "High Mass Mars Entry, Descent, and Landing Architecture Assessment," AIAA Paper 2009-6684, Sept. 2009.

${ }^{3}$ Zang, T. A., Dwyer-Dianciolo, A. M., Kinney, D. J., Howard, A. R., Chen, G. T., Ivanov, M. C., Sostaric, R. R., and Westhelle, C. H., "Overview of the NASA Entry, Descent and Landing Systems Analysis Study," AIAA Paper 2010-8649, Aug. 2010 .

${ }^{4}$ Edquist, K. T., Dyakonov, A. A., Korzun, A. M., Shidner, J. D., Studak, J. W., Tigges, M. A., Kipp, D. M., Prakash, R., Trumble, K. A., and Dupzyk, I. C., "Development of Supersonic Retro-Propulsion for Future Mars Entry, Descent, and Landing Systems," AIAA Paper 2010-5046, June 2010.

${ }^{5}$ Korzun, A. M. and Braun, R. D., "Performance Characterization of Supersonic Retropropulsion Technology for High-Mass Mars Entry Systems," Journal of Spacecraft and Rockets, Vol. 47, No. 5, Sep.-Oct. 2010.

${ }^{6}$ Korzun, A. M., Braun, R. D., and Cruz, J. R., "Survey of Supersonic Retropropulsion Technology for Mars Entry, Descent, and Landing," Journal of Spacecraft and Rockets, Vol. 46, No. 5, Sep.-Oct. 2009.

${ }^{7}$ Trumble, K. A., Schauerhamer, D. G., Kleb, W. L., Carlson, J. R., Buning, P. G., Edquist, K. T., and Barnhardt, M. D., "An Initial Assessment of Navier-Stokes Codes Applied to Supersonic Retro-Propulsion," AIAA Paper 2010-5047, June 2010.

${ }^{8}$ Trumble, K. A., Schauerhamer, D. G., Kleb, W. L., Carlson, J. R., and Edquist, K. T., "Analysis of Navier-Stokes Codes Applied to Supersonic Retro-Propulsion Wind Tunnel Test," IEEE aerospace conference paper 1471, March 2011.

${ }^{9}$ Kleb, W. L., Carlson, J., Buning, P. G., Berry, S. A., N.Rhode, R., Edquist, K. T., Schauerhamer, D. G., Trumble, K. A., and Sozer, E., "Toward Supersonic Retropropulsion CFD Validation," AIAA Paper 2011-3490, June 2011.

${ }^{10}$ Wright, M. W., White, T., and Mangini, N., "Data Parallel Line Relaxation (DPLR) Code User Manual Acadia Version 4.01.1," NASA TM-2009-215388, Oct. 2009.

${ }^{11}$ Anderson, W. K. and Bonhaus, D. L., "An Implicit Upwind Algorithm for Computing Turbulent Flows on Unstructured Grids," Computers and Fluids, Vol. 23, No. 1, 1994, pp. 1-21.

${ }^{12}$ Anderson, W. K., Rausch, R. D., and Bonhaus, D. L., "Implicit/Multigrid Algorithm for Incompressible Turbulent Flows on Unstructured Grids," Journal of Computational Physics, Vol. 128, No. 2, 1996, pp. 391-408.

${ }^{13}$ Buning, P. G., Jespersen, D. C., Pulliam, T. H., Klopfer, G. H., Chan, W. M., Slotnick, J. P., Krist, S. E., and Renze, K. J., "Overflow Users Manual," NASA Langley Research Center, Hampton, Va, 2002.

${ }^{14}$ Berry, S. A. and Rhode, M. N., "Supersonic Retro-Propulsion Test 1853 in NASA LaRC Unitary Plan Wind Tunnel Test Section 2," NASA EDL-01-TR-9178, Nov. 2010.

${ }^{15}$ Berry, S. A., Laws, C. T., Kleb, W. L., Rhode, M. N., Spells, C., Mccrea, A. C., Trumble, K. A., Schauerhamer, D. G., and Oberkampf, W. L., "Supersonic Retro-Propulsion Experimental Design for Computational Fluid Dynamics Model Validation," IEEE Aerospace Conference Paper 1499, March 2011.

${ }^{16}$ Berry, S. A., Rhode, M. N., Edquist, K. T., and Player, C. J., "Supersonic Retropropulsion Experimental Results from the NASA Langley Unitary Plan Wind Tunnel," AIAA Paper 2011-3489, June 2011.

${ }^{17}$ Jarvinen, P. O. and Adams, R. H., "The Aerodynamic Characteristics of Large Angled Cones with Retrorockets," NASA CR NAS7-576, Cambridge, MA, Feb. 1970.

${ }^{18}$ Bakhtian, N. M. and Aftosmis, M. J., "Parametric Study of Peripheral Nozzle Confgurations for Supersonic Retropropulsion," Journal of Spacecraft and Rockets, Vol. 47, No. 6, 2010, pp. 935-950.

${ }^{19}$ MacCormack, R. W. and Candler, G. V., "The Solution of the Navier-Stokes Equations Using Gauss-Seidel Line Relaxation," Computers and Fluids, Vol. 17, No. 1, 1989, pp. 135-150.

${ }^{20}$ van Leer, B., "Towards the Ultimate Conservative Scheme. V. A Second-Order Sequel to Godunov's Method," Journal of Computational Physics, Vol. 32, 1979, pp. 101-136.

${ }^{21}$ Yee, H. C., "A Class of High-Resolution Explicit and Implicit Shock Capturing Methods," NASA TM 101088, Feb. 1989.

${ }^{22}$ Menter, F. R., "Two-Equation Eddy-Viscosity Turbulence Models for Engineering Applications," AIAA Journal, Vol. 32, No. 8, 1994, pp. 1598-1605.

${ }^{23}$ Edwards, J. R., "A Low-Diffusion Flux-Splitting Scheme for Navier-Stokes Calculation," Computers and Fluids, Vol. 26, 1997, pp. 653-659.

${ }^{24}$ van Albada, G. D., van Leer, B., and Roberts, W. W., "A Comparative Study of Computational Methods in Cosmic Gas Dynamics," Astronomy and Astrophysics, Vol. 108, 1982, pp. 76.

${ }^{25}$ White, J. A., Private Communication, 2010. 
${ }^{26}$ Spalart, P. R. and Allmaras, S. R., "A One-Equation Turbulence Model for Aerodynamic Flows," AIAA Paper 92-0439, Jan. 1992.

${ }^{27}$ Vatsa, V. N., Carpenter, M. H., and Lockard, D. P., "Re-evaluation of an Optimized Second Order Backward Difference (BDF2OPT) Scheme for Unsteady Flow Applications," AIAA Paper 2010-0122, Jan. 2010.

${ }^{28}$ Tramel, R., Nichols, R., and Buning, P., "Addition of Improved Shock-Capturing Schemes to OVERFLOW 2.1," AIAA Paper 2009-3988, June 2009.

${ }^{29}$ Rhode, M. N. and Oberkampf, W. L., "Estimation of Uncertainties for Supersonic Retropropulsion Test 1853 NASA Langley Research Center Unitary Plan Wind Tunnel," NASA TR-EDL_01_TR_9217, Oct. 2011.

${ }^{30}$ Yates, L. A., "Interferograms, Schlieren, and Shadowgraphs Constructed from Real- and Ideal-Gas, Two- and ThreeDimensional Computed Flowfields," NASA CR-190054, Jan. 1992. 